\title{
THE RESEARCH OF INTERRELATION BETWEEN SEISMIC ACTIVITY AND MODERN VERTICAL MOVEMENTS OF THE EUROPEAN PERMANENT GNSS-STATIONS
}

\author{
Kornyliy TRETYAK $^{1{ }^{1 *}}$ and Volodymyr ROMANIUK ${ }^{2)}$ \\ ${ }^{1)}$ Institute of Geodesy, Lviv Polytechnic National University, 6 Karpinski Street, 79013 Lviv, Ukraine \\ 2) Institute of Environmental Engineering, Ivano-Frankivsk National Technical University of Oil and Gas, \\ 15 Karpatska Street, 76019 Ivano-Frankivsk, Ukraine \\ *Corresponding author'se-mail: kornel@1p.edu.ua; kornel1958@gmail.com
}

\section{ARTICLE INFO}

\section{Article history}

Received 17 December 2017

Accepted 29 May 2018

Available online 8 June 2018

Keywords:

seismic activity

GNSS-stations

velocity

vertical movements

\section{ABSTRACT}

Based on experimental studies using the "integral velocity index of the vertical displacement of the territory" and criterion of generalized seismicity, a close functional relationship was found between two parameters of different physical nature: seismic activity and altitude displacements of the Earth's surface in Europe. The mathematical correlation between the generalized parameters of the velocity altitude displacements on the territory and seismic activity is established according to seismic and GNSS stations for the period from 2000-2011 for the areas in Europe with close correlation between seismicity and velocity of vertical movements of the Earth's surface.

\section{INTRODUCTION}

Earthquake prediction is a difficult scientific problem and the main goal of seismology. Despite considerable scientists' efforts (Mladenovski, 1985) there is no specific methods now that can predict the time and place of seismic tremor. One way of this problem solution is to decide interrelation between seismic events and movements or deformations of the Earth surface. Especially, it has become actual with the appearance of high-precision GNSS network used for monitoring geodynamic processes slow and intermittent Earth's surface movements caused by seismic and technological factors. A great deal of information is collected from GNSS networks in seismically dangerous regions of the world based on the data of GNSS-stations before and after earthquakes. The most significant is researching with the help of high frequency kinematic GNSS- receivers of permanent stations network situated in Japanese GEONET, especially during preparative periods and at time of the disastrous 9-points magnitude earthquake on the 11th of March, 2011. However, prediction of seismic events using analysis of coseismic displacement of permanent stations is possible with the appearance of powerful earthquakes and fixation of abnormal deformations which can occur in a short period of time before the earthquake. With the development of GNSS technologies, a new direction in GNSS seismology has appeared which due to the high speed data of GNSS stations positioning technology can be applied for monitoring earthquakes in real time (Allen and Ziv, 2011; Avallone et al.
2012, 2016) and warning tsunami (Blewitt et al., 2009; Sobolev et. al., 2007). GNSS- receiver partially can replace seismograph. But GNSS receiver cannot capture high-frequency seismic vibrations and is less sensitive than seismograph, that's why according to GNSS technology it can't be applied for monitoring seismic waves of weak or distant earthquakes (Liu et al., 2012).

Using networks of GNSS stations for seismology may have another aspect. It is looking for interrelation between slow displacement of Earth's surface and generalized seismic parameters (Tretyak and Romaniuk, 2013). There are time periods when in certain regions on the whole continents seismic activity is increasing or reducing (EMSC-CSEM, USGS). In Figure 1 there is a histogram of the annual distribution of earthquakes on the territory of Europe according to the magnitude for the period 2000-2011. Each column of the histogram shows the number of earthquakes of a certain range of magnitude that occurred during a certain period. Actually generalized seismicity must display the integrated parameters of earthquakes that is the total magnitude or earthquakes power having appeared in a certain area for a certain period of time (Yokoyama and Nazzaro, 2002; Stenmark, 2014).

The task of this research is not to predict a certain seismic event but to find interrelation between the field of vertical movements of the Earth's surface and seismic activity as a whole and vice versa. It is obvious that spatial vector reflects the movements of GNSS stations under the influence of the tectonic 


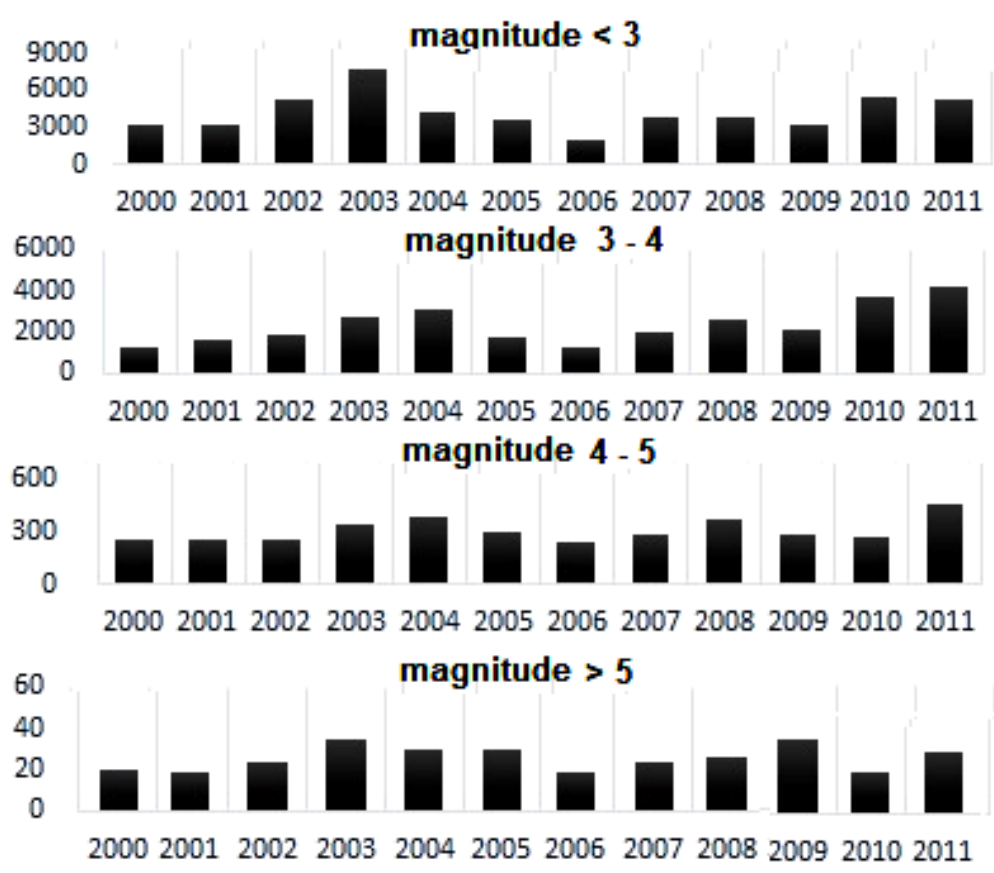

Fig. 1 Statistical distribution of the number of European earthquakes during 2000-2011. (According to the US Geological Survey National Earthquake Information Center and EuropeanMediterranean Seismological Centre).

forces. We consider only the vertical movement in order to simplify the task of searching for the correlation between generalized seismicity and generalized parameters of the Earth's motion. The relationship between vertical movements and seismicity has been established long ago (Yokoyama and Nazzaro, 2002; Dambara, 1966; Yurkevich, 1964) and is confirmed by modern technologies, in particular, InSAR, (Jung and Hong, 2017; Lu et al., 2003; Cheloni et al., 2017). Based on GNSS measurements at 33 points, significant differences were defined in the coseismic and post-seismic vertical displacement of the earthquake in Italy on April 6, 2009 (Cenni et al., 2012), and the coseismic displacement of the earthquake on August 24, 2016 in central Italy (Cheloni et al., 2016), consistent with seismic and geological data. Establishing such a correlation can allow the development of a mechanism to forecast generalized seismic activity. The connection of background deformations with strong earthquake manifestation is established in the research (Riguzzi et al., 2012, 2013), although this opinion is not supported (Cenni et al., 2015), but it offers GNSS monitoring of post-seismic displacements in order to be reconstructed, and these results are used for medium-term earthquake prediction. Based on the comprehensive analysis of GNSS networks, it is proposed to clarify the zones of possible earthquake manifestation (Panza et al., 2017). Spatial-temporal studying of the fact of the interrelation between the field of vertical movements of the Earth's surface and overall seismic activity is essential and it obviously correlates with the modern tectonic structure and modern geodynamics.
The basis for studying tectonic vertical movements is the hypothesis of their formation under the influence of vertical convection flows in the mantle layers. The movement of tectonic plates is always caused by the action of certain forces. A. Wegener assumed that the motion of tectonic plates was caused by tidal forces, or forces associated with the rotation of the Earth. However, H. Jeffreys showed that these forces were not enough (Jeffreys, 2008). The action of forces is required for displacement of tectonic plates, which will appear in the energy of earthquakes and volcanic explosions, the formation of mountains. As a hypothetical mechanism, thermal convection was proposed - vertical flows of mantle liquid. Convection can occur in a fluid that is heated below or from inside and is cooled above. As a result, colder rocks are immersed in the depth of the mantle. Hot flows rise to the inner surface of the Earth's crust and create the effect of vertical forces which create vertical movements and tension of the Earth's crust. Partially this tension leads to the occurrence of earthquakes in deep tectonic faults and energy allocation. The reflection of deep deformations can be observed in the movement of the Earth's surface in the area of the future earthquake. Abnormal movements of the Earth's surface after earthquakes represent the total magnitude, reflection of the motion of the energy accumulation and discharge periods (Rudenko et al., 2013; Altamimi, 2015; He et al., 2015; Métivier et al., 2014).

The direction of this research coincides with the various working groups activities and multifunctional services of the International Association of Geodesy (IAG), International Service GNSS, EUREF 
Permanent GPS Network, The Global Geodetic Observing System (Santamaria-Gómez, 2010), EPOS - European surveillance system for plates (Lidberg et al., 2014; Fernandes, 2014; Hatanaka et al., 2003; Pospíśil et al., 2017; Klos and Bogusz, 2017 ). One of the main tasks of these services is to study the spatial movements of the Earth's surface and their interrelation to processes occurring in lithosphere. Great attention is paid for establishing the interrelation between modern vertical movements and the forces that cause them. One of these forces is seismic force. Thus using global satellite geodesy it is possible to get not only high quality information about modern geodynamics but to observe all its spatial and place changes that is especially important for the purposes of adequate seismic zoning and finding interrelation in geodynamic processes (Joó, 1998) .

However, the accuracy of European network of GNSS stations (EPN) coordinates with daily solutions and is about of $2-3 \mathrm{~mm}$ in the plane and $3-4 \mathrm{~mm}$ in the height. This accuracy is not satisfactory for velocity mapping of vertical movements of the Earth's surface. The basic amounts of EPN GNSS stations have been operating for more than 10 years. Time periods are constructed based on their observations and are presented on the web pages of various services (IGS, EPN, SOPAC). These time periods display periodical and linear velocities. Periodic signals have a significant effect on velocity determination, but the main periodic signals are almost invested in the annual period (these are annual, half-yearly and shorter-period signals; Abraha et al., 2017). Periodic signals for more than 200 stations all around the world were investigated and it was found out that the duration of the annual period is within 349-393 days, for the European territory it is within 360-370 days (Tretyak et al., 2012). Accordingly, this periodic signal is almost offset at annual speeds. Periodic signals arise under the influence of various factors (Dong et al., 2002; Gruszczynska et al., 2017; Fang, 2002; Tretyak et al., 2015). As periodic oscillations are practically constant, they do not appear at the average velocities of vertical movements determined on the basis of long-term data processing, but the accuracy of velocity determination is different. In addition to these factors, we still get changes in the velocity of the GNSS stations connected with melting of glaciers, changes in groundwater level and in soil moisture, local geological and geomorphological conditions, and thermal expansion of buildings where satellites are installed. These impacts on restricted areas will obviously contribute anomalous component to the velocity of vertical movements of the Earth's surface. Their influence will be reduced to the results of research on the continents and with the increase of density of GNSS stations. It depends on the duration of observations and stability of the GNSS stations. For most GNSS stations, according to multidimensional measurements, the accuracy of determination of vertical velocities is within the range of 0.3-0.6 mm/year (Desai et al., 2016). This is quite a satisfactory result to determine the linear velocity that is obviously the manifestation of vertical movements of the Earth's surface. However, reducing the duration of measurements to one-two years worsens the accuracy of determining vertical velocities up to 1-2 $\mathrm{mm} / \mathrm{year}$ and more (Cenni et al., 2013; Esposito et al., 2015; Devoti et al., 2017). If the period of observations is reduced within the year, the accuracy of determination of the vertical velocity significantly increases and requires correction of time series results, taking into account the periodic signal.

It should be noted that, vertical velocity has been determined out of the results of repeated geometric leveling or tide gauge observations and it coincides with the plumb line and is attributed to the surface of geoid or quasigeoid. Vertical velocity determined with the help of GNSS-measurements coincides with the normal line and is determined in accordance with the level-surface or reference ellipsoid. Non-parallelism of plumb line and normal of the Earth's surface is small and it does not affect the difference of velocity vectors which have been out of relative level surface or reference ellipsoid. The offset point relatively to reference ellipsoid $\delta \mathrm{r}$ to the level surface $\delta \mathrm{H}$ is linked by equation: $\delta \mathrm{r}=\delta \mathrm{H}+\delta \mathrm{N}$, where $\delta \mathrm{N}$ is changing level of surface height above the ellipsoid surface. It is known that changing of $\delta \mathrm{N}$, almost for all regions of the world is by $1-2$ times less than $\delta H$, that's why its value can be negligible (Torge, 1999). Differences of these values are more related to errors using in geometric methods of leveling measurement, tide gauge observations and GNSS measurements.

This is confirmed by the concept and the basic principles of the established unified European reference system of heights. Today it is a coherent geometric and physical reference system of heights connected to the gravital field of the Earth in the form of few implementations. Thus, the direct calculation of normal heights based on GNSS-measurements and quasigeoid model can be sure widely used not only for the needs of geodesy, but for the geodynamic processing research (Marchenko et al., 2013; Ihde and Augath, 2001; Ihde and Augath, 2002).

The results of GNSS-measurements obtained in recent years on the European continent in particular show the importance of the vertical component of tectonic movements in the Earth's surface formations and in the whole lithosphere. The formation forces that determine these processes are of exogenous and endogenous nature, and zones of abnormal vertical movements coincide with seismic active territories.

\section{THE PURPOSE AND THE TASK OF THE RESEARCH}

The main purpose of the research is to establish criteria of generalized seismic activity and velocity field of vertical movements of the Earth's surface, which was determined out of GNSS station measurements. To establish a possible interrelation between generalized parameters of vertical velocity field and seismic activity in order to determine 


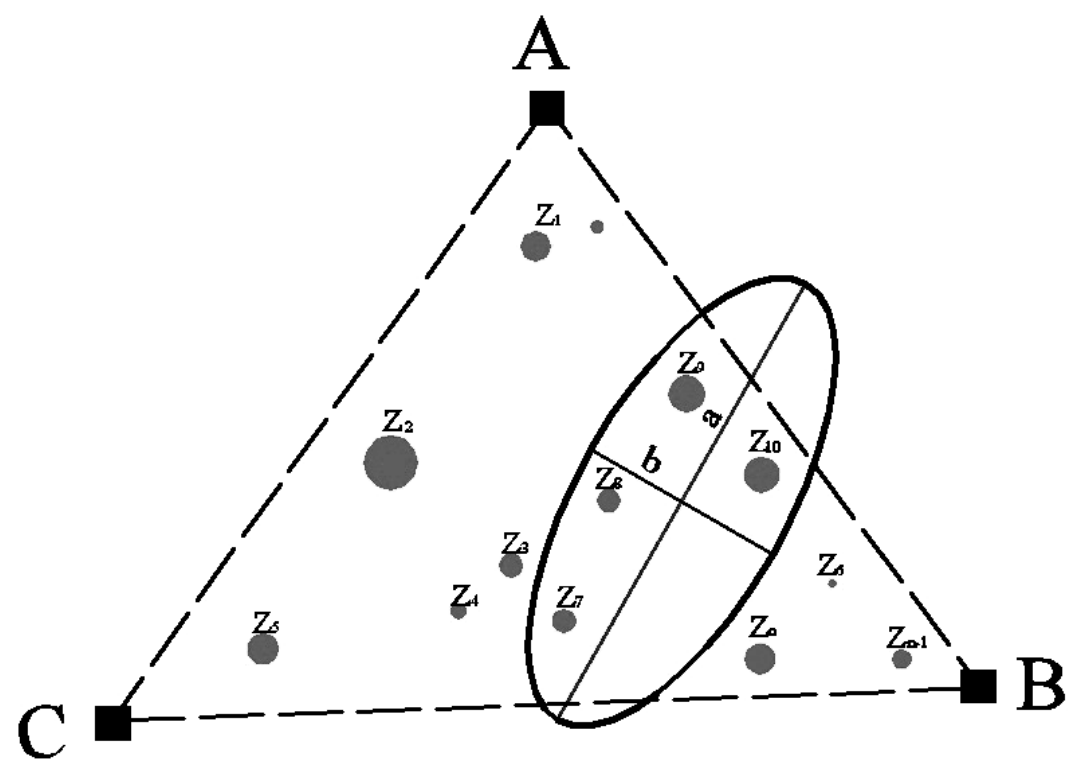

$a-$ a semi-major axis of the ellipse of scattering earthquake epicenters $b-$ a semi-minor axis of the ellipse of scattering earthquake epicenters

Fig. 2 Triangle formed by GNSS-stations, located on the territories where earthquakes of varying magnitude $\mathrm{Z1} \ldots . \mathrm{Zn}$ had been.

possible functional correlation between them. Thus, the tasks of the research are:

- to study the dynamics of modern velocity field of vertical movements of the Earth's surface applying European durable GNSS measurements;

- to create generalized criteria of vertical velocity field of the Earth's surface;

- to study spatial and temporal interrelation between the values of generalized criteria of vertical velocity field of the Earth's surface and seismicity in Europe.

\section{GENERALIZED CRITERIA OF SEISMICITY AND VERTICAL MOVEMENTS OF THE EARTH'S SURFACE}

As generalization parameters of seismicity, the total number of earthquakes of a certain magnitude, total earthquake energy, total moment seismic release and total global seismic-moment are used. Global seismic-moment appeared on a certain territory over a certain period of time (Yokoyama and Nazzaro, 2002; Ambraseys and Sarma, 1999; Bufe and Perkins, 2005; Gregersen and Basham, 2012; Zaliapin and Kreemer, 2017). However, the calculation of these parameters does not take into account the earthquake epicenters on the Earth's surface.

To generalize seismicity (Tretyak et al., 2008) it has been suggested to use ellipse of scattering earthquake epicenters. This is a statistical approach that allows us to generalize earthquakes of different magnitude and energy that have occurred over a certain period of time within a certain area (triangle). For its interpretation a special triangle, based on permanent GNSS stations A, B, C, within every epicenter of earthquakes of varying magnitude existing (Fig. 2) has been shown.

Semi-major and semi-minor axes ellipse of scattering earthquake epicenters $(a$ and $b$ ) are the values of the correlation matrix $Q$ :

$Q=\left|\begin{array}{ll}a_{11} & a_{12} \\ a_{21} & a_{22}\end{array}\right|$,

where:

$a_{11}=\sqrt{\frac{\sum_{i=1}^{n}\left[\left(x_{i}-x_{\text {mean }}\right)^{2} \cdot M_{i}\right]}{\sum_{i=1}^{n} M_{i}}}$

$a_{22}=\sqrt{\frac{\sum_{i=1}^{n}\left[\left(y_{i}-y_{\text {mean }}\right)^{2} \cdot M_{i}\right]}{\sum_{i=1}^{n} M_{i}}}$

$a_{12}=a_{21}=\sqrt{\frac{\sum_{i=1}^{n}\left[\left(x_{i}-x_{\text {mean }}\right)\left(y_{i}-y_{\text {mean }}\right) \cdot M_{i}\right]}{\sum_{i=1}^{n} M_{i}}}$

$x_{\text {mean }}=\frac{\sum_{i=1}^{n} x_{i} M_{i}}{\sum_{i=1}^{n} M_{i}}, y_{\text {mean }}=\frac{\sum_{i=1}^{n} y_{i} M_{i}}{\sum_{i=1}^{n} M_{i}}$

where:

$x_{i}, y_{i}$ - the coordinates of earthquake epicenters located within the selected triangle; 

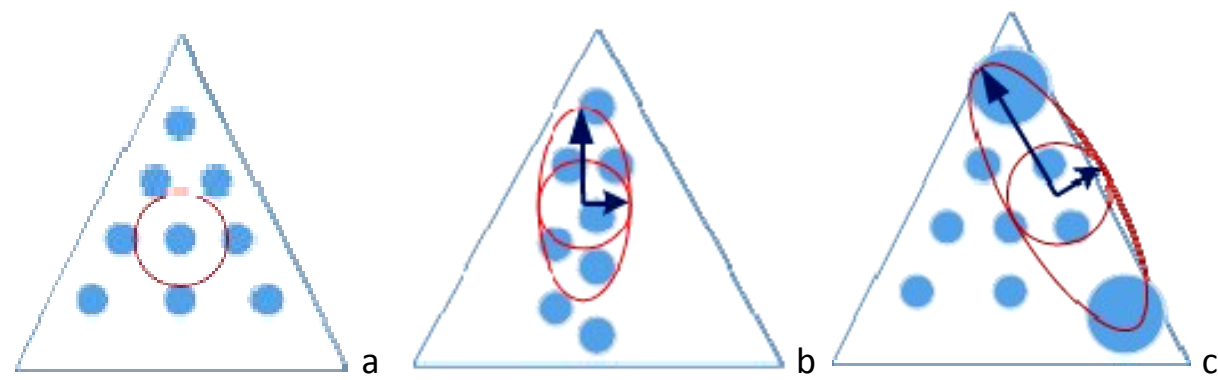

Fig. 3 Dependence of ellipsis earthquake scattering on the spatial distribution of earthquakes of different magnitudes.

$n$ is the number of earthquakes recorded for a certain period of time;

$M$ is magnitude of earthquake;

Azimuth of semi-major axis defined by the following equation:

$\theta=\left\{\begin{array}{l}\frac{1}{2} \operatorname{arctg}\left(\frac{2 a_{12}}{a_{11}^{2}-a_{22}^{2}}\right), \text { where }: a_{11} \succ a_{22} \\ \frac{1}{2} \operatorname{arctg}\left(\frac{2 a_{12}}{a_{11}^{2}-a_{22}^{2}}\right)+90^{\circ}, \text { where }: a_{11} \prec a_{22}\end{array}\right\}$

If, within the triangle, the earthquake epicenters of the same magnitude are uniformly distributed throughout the triangle, the ellipse will be the circle with a radius corresponding to the earthquake magnitude (Fig. 3a).

If the distribution of earthquakes of the same magnitude is unequal, then the splitting ellipse of the semi-major axis will be directed towards the maximum anisotropy; semi-minor axis will form a conditional circle of even distribution of earthquakes, or background area (Fig. 3b).

When abnormal magnitude earthquakes appeared on the background of the earthquakes with the same magnitude, ellipse scattering will be semi-major axis directed towards abnormal earthquakes, or maximum anisotropy and semi-minor axis will again form a conditional circle with geographically uniform distribution of small and medium magnitude earthquakes, so it means earthquakes which form seismic background (Fig. 3c).

A semi-major axis of ellipse of scattering earthquake epicenters is summarized mainly by high magnitude earthquakes, and semi-minor axis, respectively, by slack earthquakes that make up the seismic background of studying area.

There are times when the increasing seismic activity in certain regions and whole continents is observed, but it is decreasing. Having looked (Fig. 1) at histogram of earthquakes distribution it is obviously seen that the largest number of earthquakes of all magnitude range are held in 2003, 2010 and 2011, but in 2000, 2006 earthquake intensity was lower. Thus, parameters of ellipse of scattering earthquake epicenters for certain areas will differ annually.
Vertical movements of the Earth's surface display stress and deformations at the measures of tectonic blocks and the upper mantle and have obvious connection to seismic activity. Their intensity varies in time. Trends analysis of vertical displacement using the tide gauges and GNSS measurements give the possibility to reveal the age, long and short term components. For example, measured and approximated time periods of determination of vertical movements of the Earth's surface according to the tide gauge OSLO (Norway), La Coruna I (Spain) and closely set to them OSLO GNSS stations and ACOR are shown in Figure 4. Actually short-term components, which are pointed out using permanent GNSS stations, can be linked to seasonal events: not equal rotary movement of the Earth, changing atmospheric pressure, enhancing the Earth's temperature, changing groundwater levels and the accumulation of seismic deformation (Tretyak et al., 2015).

As, the vertical movements of the Earth's surface over the vast areas have general trend and some deviation from it, it is clear that short time deviation can be interpreted as a display of seismic stresses and deformations. One of the methods of finding the interrelation between these events is to establish space-time correlation between them. However, changing distribution of vertical movements of the Earth's surface in a certain area requires a generalization, as well as seismic activity does. Determination of short time vertical displacements over large territory is only possible applying the results of permanent GNSS-stations measurements. Definition of vertical movements using GNSS measurement data has a different physical approach and other error sources than traditional geometric leveling or tide gauge observations. Despite the fact that Torge in 1999 (Torge, 1999) had used these methods, he showed that the difference between surfaces of reference (reference ellipsoid and geoid) did not effect on the result of determined velocity of vertical movements of the Earth's surface. However, the experience has shown that the results of determination of vertical crust movements applying GNSS measurements and tide gauge observations do not always correlate. It can be explained by the existing different error sources, which are presented in 

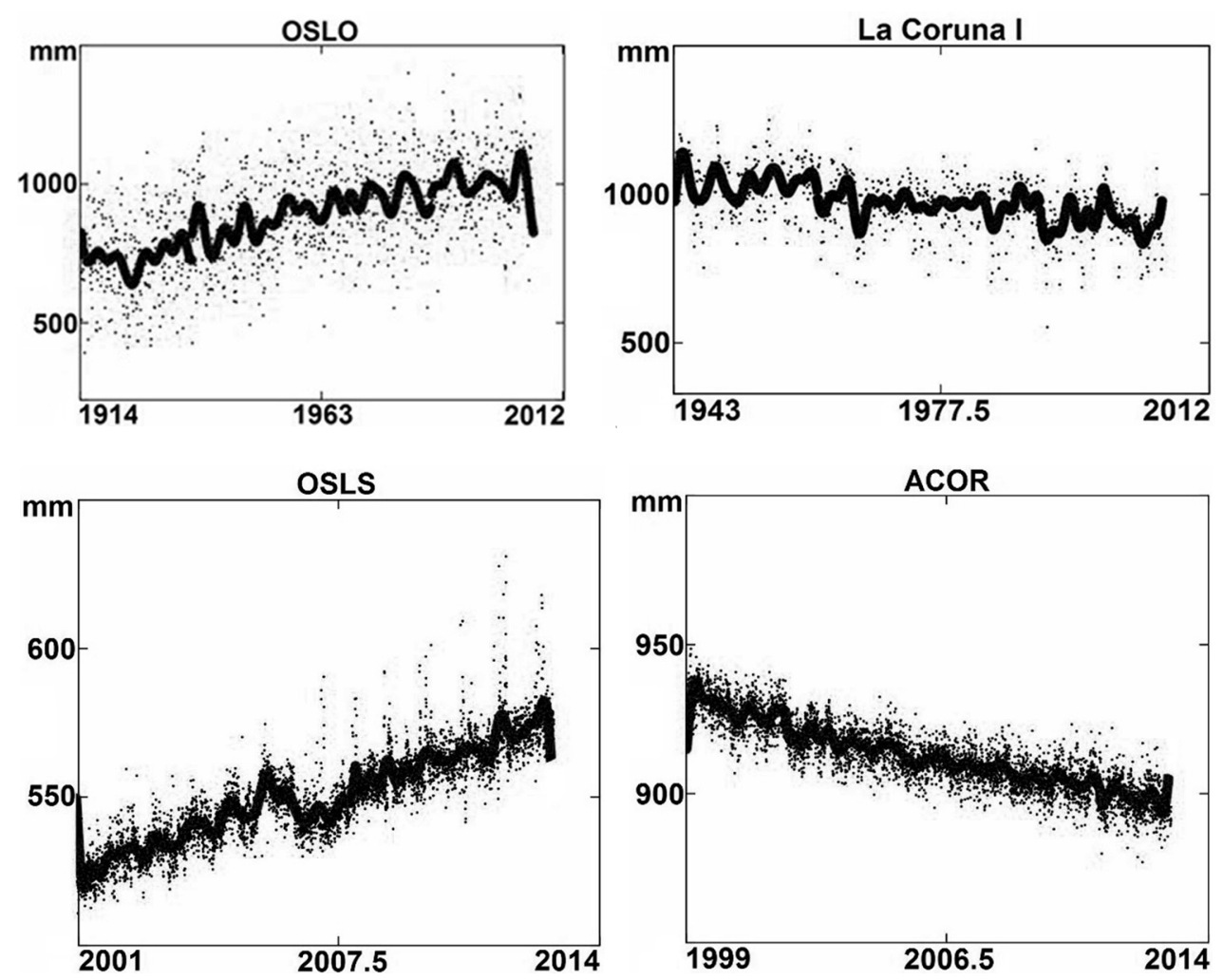

Fig. 4 Measured and approximated time periods of vertical crust movements determination using to the tide gauges of OSLO (Norway), La Coruna I (Spain) and nearby GNSS stations OSLO and ACOR.

these methods. Thus, the results obtained using tide gauge observation is distorted by onflow phenomena, salty changes, sea currents, wind directions and other factors. Ionosphere and troposphere effects, displacements of aerial phase center, changes in the spatial coordinate systems distort GNSS measurements. Nevertheless, there is better technology than GNSS measurements for monitoring vertical movements on the large territory. Taking into consideration that seismic deformations are displayed in spatial and temporal changes of the velocity of vertical crust movements thus setting them as measuring difference in time and as a result, significant part of errors shown by GNSS measurements will be compensated.

In order to implement generalized evaluation criteria of velocity of vertical movements of the Earth's surface, the concept of the integral velocity index of the vertical displacement has been adopted. Physically, it expresses the "volume" of the velocity altitude displacement of the Earth's surface. The integral velocity index of the vertical displacement is determined by equation (4):

$\delta V_{\text {int }}=S \frac{\Sigma\left|V_{i}\right|}{3}$

where:

$S$ is square of the triangle set by three permanent GNSS-stations;

$\left|V_{i}\right|$ is absolute velocity of permanent GNSS stations displacement and $i$ is apex of the triangle.
Figure 5a shows graphically vectors of the velocity of vertical movement of permanent GNSS stations of a set triangle. Within set triangle or a group of triangles integral velocity index of the vertical displacement will be presented by the total volume in dark gray color (rising area) and in gray color (lowering area) in Figure 5b.

Integral Velocity Index of the Vertical Displacement does not differentiate between elevation and lowering of the Earth's surface. However, a scalar moment of seismicity is used to generalize a seismic event and it only reflects the earthquake magnitude without detailing the spatial displacements and is determined by a similar equation as the proposed integral index of velocity altitude displacement. The scalar seismic moment $M_{0}$ is defined by the equation, where $\mu$ is the shear modulus of the rocks involved in the earthquake (in $\mathrm{Pa}$ ), $A$ is the area of the rupture along the geologic fault where the earthquake occurred (in $\mathrm{m}^{2}$ ), $D$ is the average slip on (in $\mathrm{m}$ ). Accordingly, surface displacement volume is without spatial distribution. Hence, the scalar seismic moment calculate $d$ from data of seismographs, geodetic measurements, and in paleoseismology according to geological displacements (Pancha et al., 2006; Selvaggi et al., 1997).

Any territory with set permanent GNSS-stations network can be divided into relative triangles. To do this, the best way is to apply a well-known method of triangulation by Delaunay. 

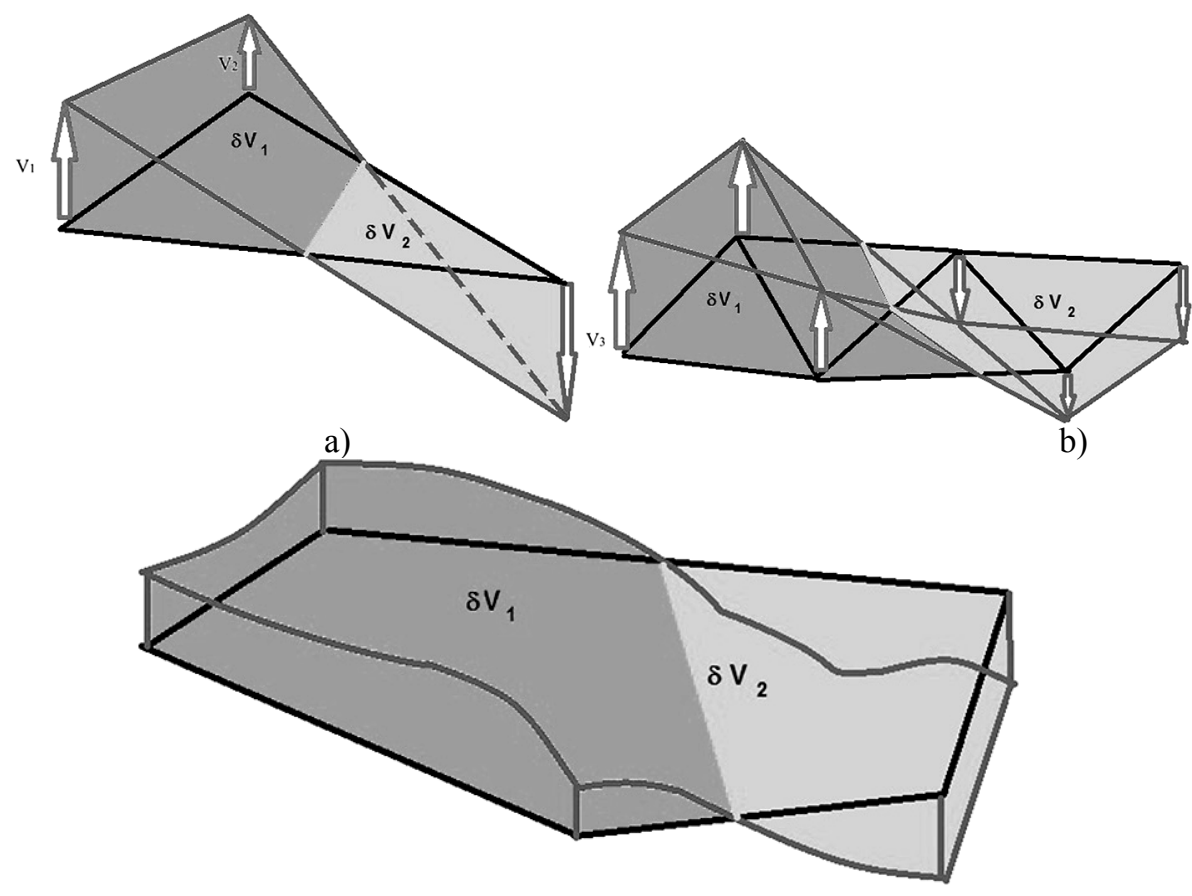

b)

c)

Fig. 5 Geometric Interpretation of Integral Velocity Index of the Vertical Displacement.

As the whole area is covered by triangles network, the total volume of velocity altitude displacement of the Earth's surface is determined by the equation (4). Thus, the numerical integration of the entire territory based on three variables $(\mathrm{x}, \mathrm{y}, \mathrm{h})$ will be the result. Physically, this is the absolute velocity volume of changing surface that is the result of vertical movements of the Earth's surface (Fig. 5c). The parameter of absolute altitude displacement of the Earth's surface is similar to the scalar moment of seismicity, which only reflects the magnitude of the earthquake without the details of special displacements.

Therefore, applying GNSS measurements it is possible to determine the integral velocity index of the vertical displacement, for a certain period of time, which will generalize the velocity field of vertical movements of the Earth's surface.

As the result, seismic activity and velocity field of vertical movements of the Earth's surface can be summarized by two criteria: ellipse of scattering earthquake epicenters and integral velocity index of the vertical displacement.

Search for space-time correlation between these parameters can be the way to establish mechanism of seismic display of vertical movements of the Earth's surface.

\section{DATA}

To analyze displaying of correlative connection of the total seismic activity and velocity field of modern vertical crust movements selected on the European territory has been perfect experimental place for this research. This is due to the presence of relatively dense network of permanent GNSS-stations with durable periods of measurements and significant territorial differentiation of seismic activity.

The output data are calculated based on the period from 2000 till 2011 the annual velocity of vertical permanent GNSS stations displacement. Coordinates and depth of the epicenter, magnitude and time of display of all earthquakes taken place in Europe during this period (according to the data presented by US Geological Survey National Earthquake Information Center, EuropeanMediterranean Seismological Centre) have been chosen. During the period from 2000 till 2011 earthquakes magnitude 7 were recorded. Earthquakes magnitude less than 1 has not been taken into account. Generalized characteristics of earthquakes displaying for the period from 2000 till 2011 are presented in Table 1.

Permanent GNSS stations network for each year measurement have been divided by Delaunay triangulation on the triangles network, the apex of which are permanent GNSS-stations. An example, using Delaunay triangulation network formed by the operating permanent GNSS-stations in 2000 is shown in Figure $6 a$.

As the number of permanent GNSS-stations is increasing each year, thus the density of operating triangles network is increasing too. Figure $6 \mathrm{~b}$ shows the triangles network formed by permanent GNSSstations in 2011. Based on the set up factors of earthquakes and annual created maps of triangles networks the division of selected earthquakes within each group has been done. Earthquakes, the epicenters of which are located within the measures of the set triangle are included in a separate group. 
Table 1 The generalized characteristics of earthquakes displaying on the European continent (for the period from 2000 till 2011).

\begin{tabular}{cccc}
\hline Year & Number of earthquakes & Max magnitude & Average magnitude \\
\hline 2000 & 4646 & 4.5 & 2.51 \\
2001 & 5105 & 6.5 & 2.62 \\
2002 & 7261 & 6.0 & 2.55 \\
2003 & 10704 & 6.8 & 2.36 \\
2004 & 7750 & 6.4 & 2.53 \\
2005 & 2733 & 5.7 & 2.97 \\
2006 & 3364 & 6.7 & 2.91 \\
2007 & 4902 & 5.7 & 2.87 \\
2008 & 4712 & 6.9 & 3.02 \\
2009 & 5643 & 6.5 & 2.81 \\
2010 & 8376 & 6.3 & 2.57 \\
2011 & 10009 & 6.2 & 2.51 \\
\hline
\end{tabular}

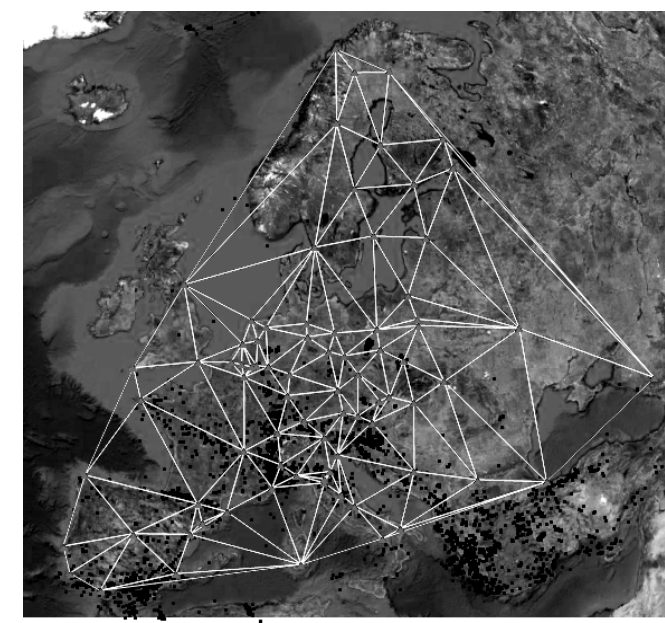

a)

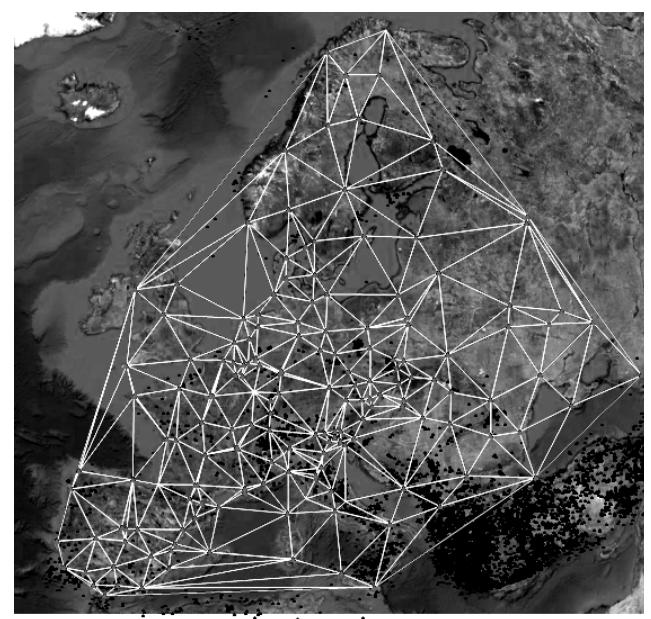

b)

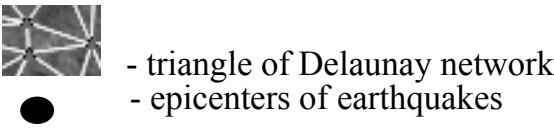

Fig. 6 Network Delaunay triangulation formed by permanent operating GNSS-stations for the period from 2000 till 2011.

Besides information about the earthquakes, the database includes information about the average annual vertical velocity of GNSS stations, so it means the name of permanent station, its latitude and longitude and the annual average vertical velocity.

Daily output results for vertical velocity of GNSS stations were calculated by Nevada Geodetic Laboratory with the GIPSY-OASIS-II software from Precise Point Positioning

(http:/geodesy.unr.edu/gps/ngl.acn.txt), and time series are available on the NGL website. The selection of stations was carried out provided that its time series are virtually continuous, including 2011. The annual time series with a data amount of not less than $90 \%$ were accepted for processing. Rough mistakes were withdrawn from time series. The criterion of rough mistake was the change in station altitude during one day at a value greater than $20 \mathrm{~mm}$. In addition, correction was made to change the antenna altitude from the Sitelog files of the station. The annual vertical velocity and its accuracy were determined by the method of least squares. Generalized vertical velocity parameters of permanent stations for the period from 2000 till 2011 are presented in Table 2. It is obvious that during the period of observations significant fluctuations of extreme velocities of rising and lowering of the territory have been recorded. It especially concerns negative velocities.

\section{INVESTIGATION OF INTERRELATION BETWEEN SEISMICITY AND VERTICAL MOVEMENTS OF THE EARTH'S SURFACE IN EUROPE}

The process of investigation of interrelation between generalized seismic criteria and vertical movements of the Earth's surface is set on the base of 2011 data. As a result, the location of earthquake epicenters relatively to triangles networks during 2011 has been shown in Figure $6 b$.

Table 3 shows the part of coordinates base and the velocity of vertical displacement of permanent GNSS stations in 2011, which is formed by the apex of triangles. For this period, the velocity of vertical movement is in the range from $-9.4 \mathrm{~mm}$ per year (station AXPV) to $9.09 \mathrm{~mm}$ per year (station BAIA). Negative values of velocities correspond to lowering territory and positive corresponds to rising territory of permanent GNSS stations. 
Table 2 The generalized characteristic of the velocity of vertical movements of the Earth's surface for the period since 2000 till 2011.

\begin{tabular}{ccccc}
\hline Year & $\begin{array}{c}\text { Number of GNSS } \\
\text { stations }\end{array}$ & $\begin{array}{c}\text { Min. velocity } \\
\text { (Lowering of } \\
\text { territory) }\end{array}$ & $\begin{array}{c}\text { Max. velocity } \\
\text { (Rising of territory) }\end{array}$ & Average velocity \\
\hline 2000 & 81 & -11.5 & 20.5 & 3.9 \\
2001 & 100 & -9.8 & 16.4 & 0.5 \\
2002 & 125 & -24.2 & 16.4 & -2.1 \\
2003 & 150 & -18.8 & 20.4 & 4.5 \\
2004 & 158 & -12.2 & 21.0 & 5.5 \\
2005 & 162 & -23.8 & 18.4 & 7.3 \\
2006 & 169 & -22.6 & 19.5 & -0.7 \\
2007 & 173 & -20.6 & 26.5 & 3.5 \\
2008 & 178 & -15.2 & 16.5 & 5.6 \\
2009 & 185 & -6.8 & 18.5 & 3.7 \\
2010 & 185 & -16.3 & 24.6 & 1.9 \\
\hline
\end{tabular}

Table 3 Part of average annual data of vertical GNSS stations velocity in 2011.

\begin{tabular}{|c|c|c|c|c|c|c|c|c|c|c|c|}
\hline \multirow{2}{*}{$\begin{array}{l}\dot{\bar{D}} \\
\text { 离 } \\
\text { z }\end{array}$} & \multirow{2}{*}{$\begin{array}{c}\text { The } \\
\text { name of } \\
\text { GNSS } \\
\text { station }\end{array}$} & \multicolumn{2}{|c|}{$\begin{array}{c}\text { GNSS station } \\
\text { coordinates }\end{array}$} & \multirow{2}{*}{$\begin{array}{c}\text { Velocity of } \\
\text { displacement } \\
V, \text { (mm/year) }\end{array}$} & \multirow{2}{*}{$\begin{array}{c}\text { Average } \\
\text { square } \\
\text { error } \\
V \\
(\mathrm{~mm} / \text { year) }\end{array}$} & \multirow{2}{*}{$\begin{array}{l}\text { 岕 } \\
\text { 志 } \\
\text { z }\end{array}$} & \multirow{2}{*}{$\begin{array}{l}\text { The name } \\
\text { of GNSS } \\
\text { station }\end{array}$} & \multicolumn{2}{|c|}{$\begin{array}{c}\text { GNSS station } \\
\text { coordinates }\end{array}$} & \multirow{2}{*}{$\begin{array}{l}\text { Velocity of } \\
\text { displacement } \\
V, \text { (mm/year) }\end{array}$} & \multirow{2}{*}{$\begin{array}{c}\text { Average } \\
\text { square error } \\
V, \\
(\mathrm{~mm} / \text { year })\end{array}$} \\
\hline & & $\begin{array}{c}B, \\
\text { Latitude }\end{array}$ & $\begin{array}{c}L, \\
\text { Longitude }\end{array}$ & & & & & $\begin{array}{c}B, \\
\text { Latitude }\end{array}$ & $\begin{array}{c}\text { L, } \\
\text { Longitude }\end{array}$ & & \\
\hline 1 & ACOM & 46.5 & 13.51 & 2.4 & 0.9 & 11 & AXPV & 43.49 & 5.33 & 1.8 & 1.3 \\
\hline 2 & ACOR & 43.3 & -8.40 & -3.2 & 1.0 & 12 & BACA & 46.56 & 26.9 & 6.3 & 1.1 \\
\hline 3 & AFAL & 46.5 & 12.17 & 5.7 & 0.9 & 13 & BADH & 50.22 & 8.60 & 1.7 & 1.1 \\
\hline 4 & AJAC & $4 \overline{1}, 9$ & 8.76 & 1.2 & 0.5 & 14 & BAIA & 47.65 & 23.5 & 8.9 & 1.1 \\
\hline 5 & ALAC & 38.3 & -0.48 & -2.7 & 1.0 & 15 & BBYS & 48.75 & $19 . \overline{1}$ & 1.8 & 1.1 \\
\hline 6 & ALBA & 38.9 & -1.85 & -8.5 & 0.9 & 16 & BELF & 54.57 & $-5.9 \overline{3}$ & -9.4 & 1.2 \\
\hline 7 & ALCI & $4 \overline{8} .4$ & 38.90 & 8.4 & 1.4 & 17 & BELL & 41.59 & 1.40 & -6.9 & 1.1 \\
\hline 8 & ALME & 36.8 & -2.45 & -3.9 & 1.1 & 18 & BOGI & 52.47 & 21.0 & 2.7 & 1.2 \\
\hline 9 & AQUI & 42.3 & 13.35 & 5.7 & 1.1 & 19 & BOGO & 52.47 & 21.0 & 3.8 & 1.2 \\
\hline 1 & AUTN & 46.9 & 4.28 & -1.9 & 0.9 & 20 & BOLG & 44.50 & $11 . \overline{3}$ & 1.7 & 1.4 \\
\hline
\end{tabular}

Table 4 shows the part of earthquake database of 2011 , exactly earthquakes that occurred on the 1 st of January, 2011 in Europe.

Table 5 shows that the part of calculative results for ellipse parameters of scattering earthquake epicenters and values of the integral velocity index of the vertical displacement in 2011.

An example of mapping located ellipses of scattering earthquake epicenters in Europe during 2011 is shown graphically in Figure 7.

The comparative analysis of the semi axis of ellipse of scattering earthquake epicenters and integral velocity index of the vertical displacement have been conducted in order to set correlation between generalized parameters of vertical movements of the Earth's surface and seismicity.

The first analysis was conducted to set correlation between the semi-minor axis of the ellipse of scattering earthquake epicenters, which corresponds to the background seismicity $(b)$ and the absolute value of integral velocity index of the vertical displacement on the territory $\left(\left|\delta V_{\text {int }}\right|\right)$. Two triangles were determined from the formed annual data, which corresponds to the maximum correlation between the generalized displacement parameters $b$ and $\left|\delta V_{\text {int }}\right|$. In
2011 there were the 20th and 17th triangles with the correlation coefficient of 1 (Table 6 ).

Further processing shows that the row of set triangles is increasing based on criteria of maximum correlation coefficient of ellipse of scattering earthquake epicenters of semi-minor axis and integral velocity index of the vertical displacement.

An example of changing the correlation coefficient depending on increasing number of selected triangles in 2011 according to the established criteria is shown in Figure 8a. It is clear that with increasing number of triangles its correlation coefficient is decreasing. However, this curve is characterized by beginning of slow decreasing (up to triangle 16), and then decreasing at once. It is obvious that the priority of selected triangles has close correlation between semi-minor axis of ellipse of scattering earthquake epicenters and integral velocity index of the vertical displacement. It is characterized by slow decreasing of the correlation coefficient. Further with the beginning of the correlation coefficient decreasing for this set the triangles which have no dependence or interrelation between the vertical displacement or background seismic activity are included. After having selected triangle 45 rapid 
Table 4 Database of earthquakes in Europe on January 1, 2011.

\begin{tabular}{ccccll}
\hline Date & Time UTC & $\begin{array}{c}\text { Latitude } \\
B\end{array}$ & $\begin{array}{c}\text { Longitude } \\
L\end{array}$ & Magnitude & Country \\
\hline 01.01 .2011 & $2: 48: 02$ & 43.16 & 18.78 & 2.8 & Montenegro \\
01.01 .2011 & $7: 39: 39$ & 39.98 & 20.59 & 2.6 & Greece \\
01.01 .2011 & $8: 11: 03$ & 38.32 & 16.02 & 2.3 & Italy \\
01.01 .2011 & $9: 03: 31$ & 37.06 & -4.89 & 2.6 & Spain \\
01.01 .2011 & $13: 04: 31$ & 42.97 & 13.14 & 2.0 & Italy \\
01.01 .2011 & $11: 44: 28$ & 43.26 & 12.55 & 2.0 & Italy \\
01.01 .2011 & $13: 12: 54$ & 35.85 & 23.17 & 2.2 & Greece \\
01.01 .2011 & $16: 57: 06$ & 45.60 & 26.53 & 3.1 & Romania \\
01.01 .2011 & $17: 18: 44$ & 43.16 & 18.66 & 2.2 & Bosnia and Herzegovina \\
\hline
\end{tabular}

Table 5 Part of generalized seismic parameters of velocity field of modern vertical crust movements in 2011.

\begin{tabular}{|c|c|c|c|c|c|c|c|c|}
\hline \multirow{2}{*}{$\begin{array}{l}\text { The } \\
\text { number } \\
\text { of } \\
\text { triangle }\end{array}$} & \multicolumn{3}{|c|}{ The names apex of triangle } & \multirow{2}{*}{$\begin{array}{l}\text { Semi- } \\
\text { major } \\
\text { axis } a, \\
(\mathrm{~km})\end{array}$} & \multirow{2}{*}{$\begin{array}{l}\text { Semi- } \\
\text { major } \\
\text { axis } b \text {, } \\
(\mathrm{km})\end{array}$} & \multirow{2}{*}{$\begin{array}{l}\text { Azimuth } \\
\text { of semi- } \\
\text { major axis } \\
\theta,\left({ }^{\circ}\right)\end{array}$} & \multirow{2}{*}{$\begin{array}{c}\delta V_{\text {int }} \\
10^{-3} \\
\left(\mathrm{~km}^{3} \text { per year }\right)\end{array}$} & \multirow{2}{*}{$\begin{array}{c}\left|\delta V_{\text {int }}\right| \\
10^{-3} \\
\left(\mathrm{~km}^{3} \text { per year }\right)\end{array}$} \\
\hline & $\mathrm{I}$ & II & III & & & & & \\
\hline 1 & 2 & 3 & 4 & 5 & 6 & 7 & 8 & 9 \\
\hline 1 & HERT & NEWL & CAEN & 37.49 & 2.71 & 16.94 & 0.77 & 5.65 \\
\hline 2 & OPMT & DENT & HERT & 7.35 & 1.92 & 155.50 & -0.04 & 3.25 \\
\hline 3 & CHIZ & SCOA & TLMF & 95.15 & 4.41 & 167.25 & 12.74 & 12.74 \\
\hline 4 & VIGO & $\mathrm{CACE}$ & CEBR & 15.57 & 6.53 & 145.49 & 13.60 & 13.60 \\
\hline 5 & BSCN & METZ & AUTN & 17.34 & 3.42 & 37.54 & 8.60 & 8.60 \\
\hline 6 & PRAT & BRAS & GENO & 16.56 & 2.35 & 174.80 & 1.15 & 1.15 \\
\hline 7 & ELBA & UNPG & PRAT & 13.53 & 2.97 & 157.62 & 1.38 & 5.16 \\
\hline 8 & MEDI & BOLG & BRAS & 4.89 & 0.86 & 139.67 & 0.13 & 0.13 \\
\hline 9 & BZRG & CANV & AFAL & 16.31 & 1.62 & 151.75 & 0.74 & 0.74 \\
\hline 10 & OSLS & GRAZ & GSR1 & 69.20 & 9.60 & 37.20 & -9.76 & 24.69 \\
\hline 11 & DEVA & SOFI & BUCU & 86.50 & 14.06 & 15.85 & 38.35 & 38.35 \\
\hline 12 & ZYWI & KRAW & KATO & 7.91 & 2.68 & 15,54 & 0.60 & 0.66 \\
\hline 13 & RIGA & MAR6 & VIS0 & 38.62 & 22.45 & 176.58 & 53.31 & 53.31 \\
\hline 14 & KLOP & LEIJ & РTBB & 41.69 & 10.03 & 153.97 & 8.29 & 26.94 \\
\hline 15 & PRAT & MEDI & BRAS & 3.89 & 1.53 & 142.40 & 0.23 & 0.23 \\
\hline 16 & MPRA & AFAL & CANV & 5.79 & 1.28 & 39.99 & 0.64 & 0.64 \\
\hline 17 & SOFI & ISTA & BUCU & 64.88 & 31.74 & 149.84 & 75.76 & 75.76 \\
\hline 18 & KUNZ & GOPE & WTZR & 7.66 & 4.22 & 6.13 & 1.25 & 9.15 \\
\hline 19 & ALME & CEU1 & NOT1 & 121.10 & 8.56 & 1.66 & -2.77 & 19.64 \\
\hline 20 & LAGO & CEU1 & SFER & 51.90 & 1.34 & 149.85 & 1.77 & 1.77 \\
\hline
\end{tabular}

decreasing of the correlation coefficient starts. It explains selection after triangle 45 .

These triangles do not have correlative connection of the studying parameters. As the result selected triangles can be divided into three groups. The first group within the first 16 triangles has almost $100 \%$ correlation between $\mathrm{b}$ and $\left|\delta V_{\text {int }}\right|$. The second group is from triangle 16 to triangle 45 and it has a relatively high correlation degree of studying parameters. The third group which is next to triangle 45 has no interrelation between these parameters.

Changing dependence of integral velocity index of the vertical displacement and semi-minor axis of ellipse of scattering earthquake epicenters for the 16 selected triangles with a degree of correlation more than 0.998 in 2011 is shown in Figure 9a.

Figure $9 \mathrm{~b}$ shows that the increasing number of selected triangles is decreasing the dependence between these parameters, but for selected triangles 45 the curves of changing $b$ and $\left|\delta V_{\text {int }}\right|$ are almost the same, and the correlation coefficient is not more than 0.96. Figure 9c shows that curves of changing $b$ and $\left|\delta V_{\text {int }}\right|$ next to triangle 45 do not have convergence. So, connection between these parameters is sure to be lost.
Thus, visually it can be seen that for the set areas there is a close functional interrelation between two different physical values: seismic activity and altitude displacements of the Earth's surface.

Similarly, trends of changing correlation coefficient with increasing number of selected triangles are usually for all observation years (for the period from 2000 to 2011). The total number of triangles of the first and the second groups have high degree of correlation and its correlation coefficient is shown in Table 7.

The same study was conducted to set correlation between the semi-major axis of the ellipse of scattering earthquake epicenters and the absolute value of the integral velocity index of the vertical displacement on the territory $\left(\delta V_{\text {int }}\right)$. According to the results of these studies, a graph (Fig. 7b) of the change in the correlation coefficient was constructed, depending on the growth of the selected number of triangles for 2011 on the criterion of maintaining the maximum correlation between $a$ and $\left|\delta V_{\text {int }}\right|$. The correlation coefficient is rapidly falling with the increase in the number of selected triangles. This shows lack of correlation connections between the 


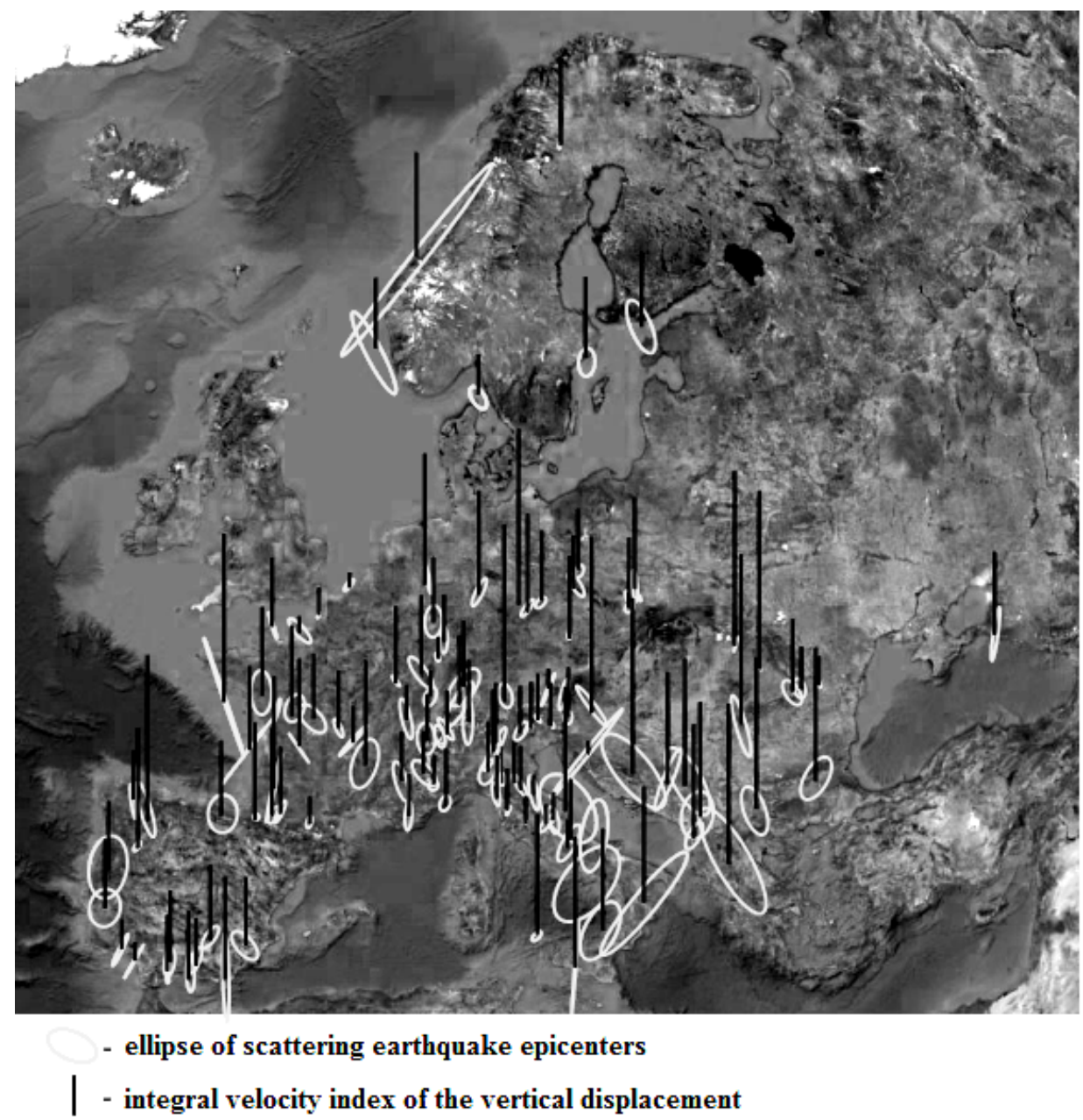

Fig. 7 Map of ellipse of scattering earthquake epicenters in Europe and integral velocity index of the vertical displacement in 2011.

Table 6 The selected triangles by applying the criterion of maximum correlation coefficient between parameters $b$ and $\left|\delta V_{\text {int }}\right|$ based on seismic activity and GNSS- stations measurements in 2011.

\begin{tabular}{|c|c|c|c|c|c|c|c|c|c|}
\hline \multirow[t]{2}{*}{ № } & \multirow{2}{*}{$\begin{array}{c}\text { The } \\
\text { number } \\
\text { of } \\
\text { triangle }\end{array}$} & \multicolumn{3}{|c|}{ The apex of triangle } & \multirow{2}{*}{$\begin{array}{l}\text { Semi-minor } \\
\text { axis } b, \\
(\mathrm{~km})\end{array}$} & \multirow{2}{*}{$\begin{array}{c}\left|\delta V_{\text {int }}\right| 10^{-5} \\
\left(\mathrm{~km}^{3} \text { per }\right. \\
\text { year })\end{array}$} & \multirow{2}{*}{$\begin{array}{c}\text { Correlation } \\
\text { coefficient } \\
K\end{array}$} & \multirow[t]{2}{*}{$\ln (b)$} & \multirow[t]{2}{*}{$\ln \left|\delta V_{\text {int }}\right|$} \\
\hline & & I & II & III & & & & & \\
\hline 1 & 20 & LAGO & CEU1 & SFER & 1.34 & 1.76 & - & 0.29 & 0.57 \\
\hline 2 & 17 & SOFI & ISTA & BUCU & 31.75 & 75.76 & 1 & 3.46 & 4.33 \\
\hline 3 & 13 & RIGA & MAR6 & VIS0 & 22.44 & 53.31 & 1 & 3.11 & 3.98 \\
\hline 4 & 18 & KUNZ & GOPE & WTZR & 4.22 & 9.15 & 1 & 1.44 & 2.21 \\
\hline 5 & 2 & OPMT & DENT & HERT & 1.92 & 3.25 & 1 & 0.65 & 1.18 \\
\hline 6 & 19 & ALME & CEU1 & NOT1 & 8.56 & 19.64 & 1 & 2.15 & 2.98 \\
\hline 7 & 1 & HERT & NEWL & CAEN & 2.71 & 5.65 & 1 & 1.00 & 1.73 \\
\hline 8 & 7 & ELBA & UNPG & PRAT & 2.97 & 5.16 & 1 & 1.09 & 1.64 \\
\hline 9 & 8 & MEDI & BOLG & BRAS & 0.86 & 0.13 & 1 & -0.15 & -2.04 \\
\hline 10 & 4 & VIGO & CACE & CEBR & 6.53 & 13.59 & 1 & 1.88 & 2.61 \\
\hline 11 & 16 & MPRA & AFAL & CANV & 1.28 & 0.64 & 1 & 0.25 & -0.45 \\
\hline 12 & 9 & BZRG & CANV & AFAL & 1.62 & 0.74 & 1 & 0.48 & -0.30 \\
\hline 13 & 5 & $\mathrm{BSCN}$ & METZ & AUTN & 3.42 & 8.60 & 1 & 1.23 & 2.15 \\
\hline 14 & 10 & OSLS & GRAZ & GSR1 & 9.60 & 24.69 & 0.999 & 2.26 & 3.21 \\
\hline 15 & 6 & PRAT & BRAS & GENO & 2.35 & 1.15 & 0.999 & 0.85 & 0.14 \\
\hline 16 & 3 & CHIZ & SCOA & TLMF & 4.41 & 12.74 & 0.998 & 1.48 & 2.54 \\
\hline 17 & 14 & KLOP & LEIJ & PTBB & 10.03 & 26.94 & 0.998 & 2.31 & 3.29 \\
\hline 18 & 15 & PRAT & MEDI & BRAS & 1.53 & 0.23 & 0.997 & 0.43 & -1.47 \\
\hline 19 & 12 & ZYWI & KRAW & KATO & 2.68 & 0.66 & 0.996 & 0.99 & -0.42 \\
\hline 20 & 11 & DEVA & SOFI & BUCU & 14.05 & 38.35 & 0.995 & 2.64 & 3.65 \\
\hline
\end{tabular}




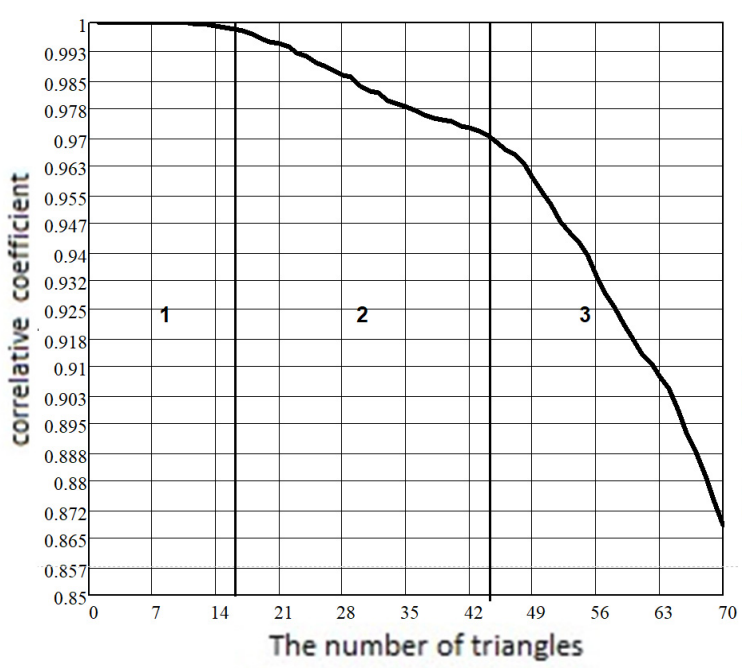

1, 2, 3 - triangle groups

a)

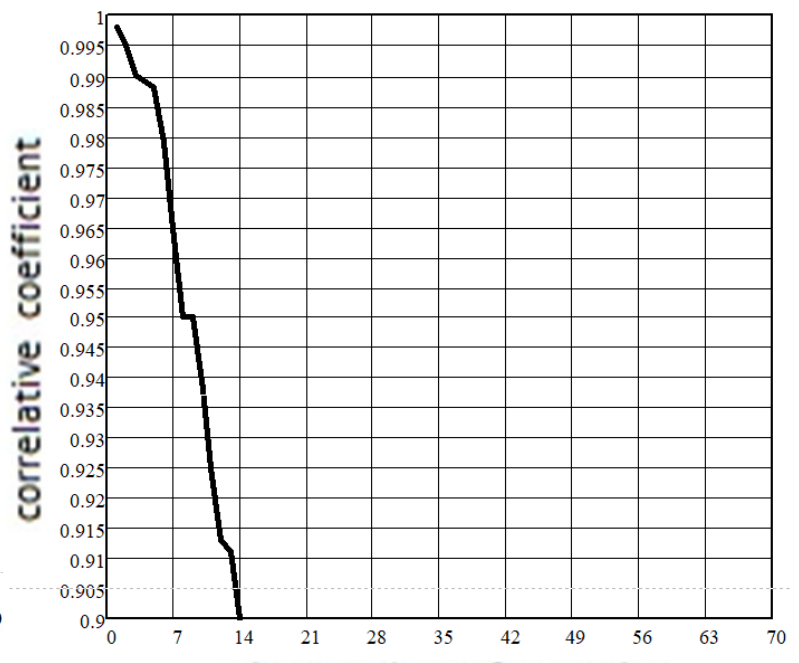

The number of triangles

b)

Fig. 8 Curve of reduction correlation coefficient in the set of triangles between generalized parameters (a) $b$ and $\left|\delta V_{\text {int }}\right|$, (b) $a$ and $\left|\delta V_{\text {int }}\right|$ in 2011.

semi-major axis of the ellipse of scattering earthquake epicenters and the integral velocity index of the vertical displacement on the territory $\left(\left|\delta V_{\text {int }}\right|\right)$.

In order to find interrelation between the parameters $\left|\delta V_{\text {int }}\right|$ and $b$ on the European territory function has been set for these two parameters of triangles with high degree of correlation. To do this, according to Table 6 , a schedule of changing the parameters $\ln (b)$ and $\ln \left|\delta V_{\text {int }}\right|$ will be constructed (Fig. 10). From this figure it can be seen that the dependence of these parameters is actually linear.

Accordingly, the equation of dependence of these parameters will be the following:

$$
\ln (b)=a \ln \left(\delta V_{\text {int }} \mid\right)+c \text {, }
$$

where:

$b$ is the value of semi-minor axis of ellipse of scattering earthquake epicenters;

$\left|\delta V_{\text {int }}\right|$ is integral velocity index of the vertical displacement, $a$ and $c$ are constant coefficients.

The results of determination of the coefficients $a$ and $c$ based on the system of equations (5), by formed selected triangles of the first and the second group using the method of the least squares have been shown in Table 7. Thus, the results obtained by processing values of coefficients $a$ and $c$ are much bigger than average square error. It shows close functional connection by the equation (5) of semiminor axis of ellipse of scattering earthquake epicenters and integral velocity index of the vertical displacement. Accuracy $m(b)$ determining $b$ in the equation (5) is from 10 to $15 \%$ of the maximum $b$ value.

Reliability of approximation $b$ of semi-minor axis of ellipse of scattering earthquake epicenters in equation (5) using data of 2011 (see Fig. 11) has been illustrated. Figure 11 shows that the maximum set of the curves of changing parameter $b$, are in triangles with the maximum $b$ values. In general, the selected function (5) with high approximation describes the dependence between $b$ and $\left|\delta V_{\text {int }}\right|$.

Similar patterns are presented for all other observation years. To analyze the dependence of $a$ and $c$ coefficients out of $b$ coefficient using data out of Table 7 graphics of dependence $a$ coefficient out of maximum changing coefficient $b$ that is $\max (b)-\min (b)$ and $c$ coefficient out of $\max$ (b) - $\min (b)$ has been created (Fig. 12) .

Figure 11 shows that the coefficients $a$ and $c$ have a linear dependence on $\max (b)-\min (b)$. Thus, for each observation year linear equation can be applied depending on $a$ and $c$ coefficients out of $\max$ (b) -min (b). Having calculated, these two systems of equations by using method of the least squares the following two equations can be done.

$$
\begin{aligned}
a & =0.007(\max (b)-\min (b))+0.23 \\
c & =0.046(\max (b)-\min (b))+2.64
\end{aligned}
$$

The average square error of determination $a$ and $c$ relatively is $m_{a}=0.1, m_{c}=0.6$ that is approximately $15 \%$ of their average values. Simple equation transformation can been done by substituting equation (6) and (5) and calculating them.

$\left|\delta V_{i H m}\right|=e^{\frac{\ln (b)-0.046(\max (b)-\min (b))+2.64}{0.007(\max (b)-\min (b))+0.23}}$

This equation gives the possibility for the territories with close correlation connection between $b$ and $\left|\delta V_{\text {int }}\right|$ based on the earthquake distribution parameters, exactly on the semi-minor axis of ellipse of scattering earthquake epicenters $b$ and integral velocity index of the vertical displacement $\left|\delta V_{\text {int }}\right|$, which shows the intensity of vertical movements of the Earth's surface. The reliability of expression (7) is illustrated in Figure 13.

It must be noted that the maximum deviation between $\left|\delta V_{\text {int }}\right|$. which is determined by measuring 

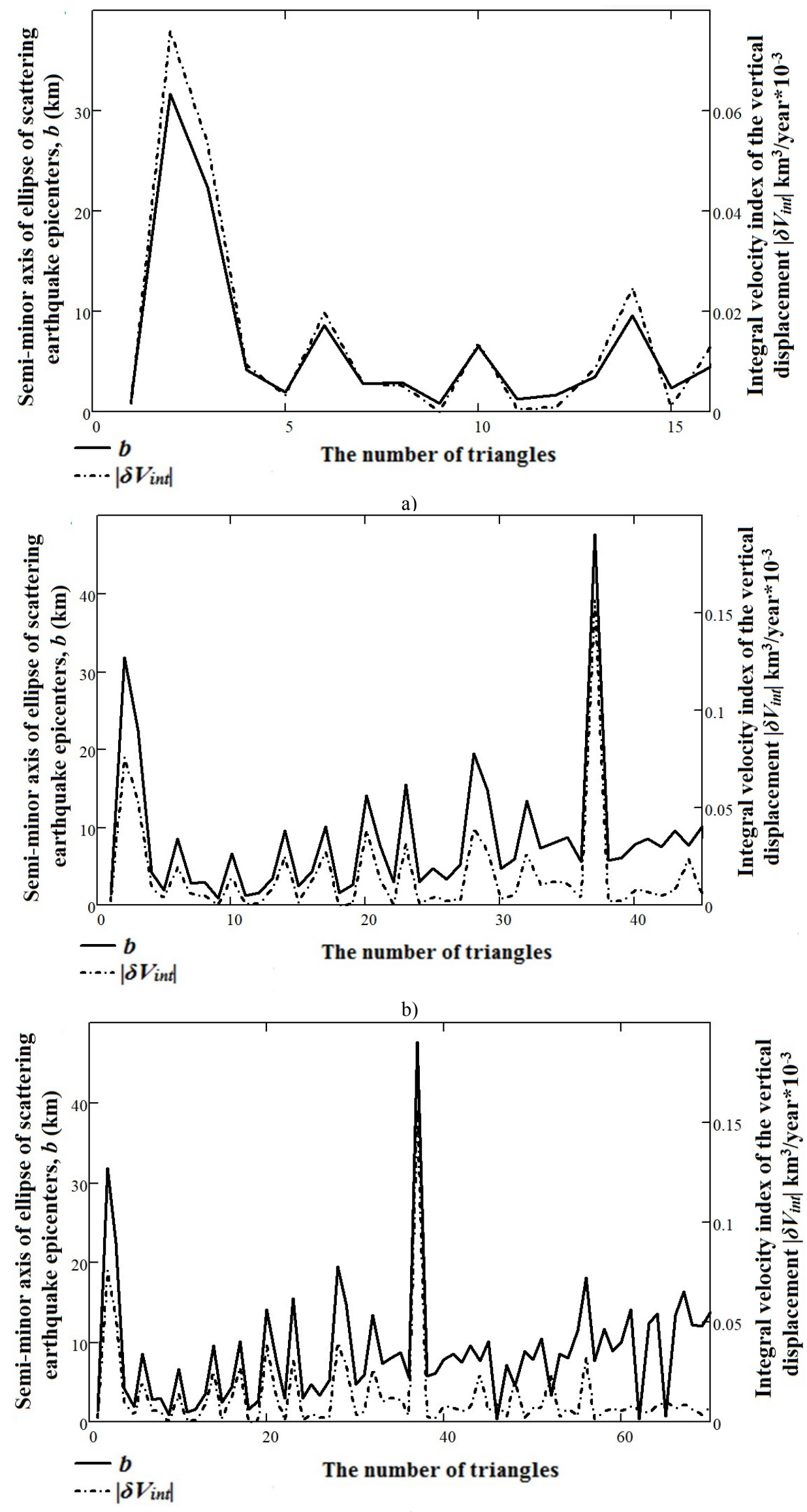

c)

Fig. 9 Changing of semi-minor axis of ellipse of scattering earthquake epicenters and integral velocity index of the vertical displacement in 2011. (a) is for 16 selected triangles; b) is for 45 selected triangles; c) is for 70 selected triangles). 
Table 7 Annual values of correlation $c$ and $a$ coefficients. Their accuracy according to the results in the period from 2000 till 2011.

\begin{tabular}{|c|c|c|c|c|c|c|c|c|c|}
\hline Year & $\begin{array}{c}\text { The } \\
\text { number of } \\
\text { triangles }\end{array}$ & $\begin{array}{l}\text { Correlation } \\
\text { coefficient }\end{array}$ & $a$ & $m_{a}$ & $c$ & $m_{c}$ & $\begin{array}{l}m(b) \text { by the } \\
\text { equation }(5) \\
(\mathrm{km})\end{array}$ & $\begin{array}{l}\text { Min } \\
\text { (b) } \\
(\mathrm{km})\end{array}$ & $\begin{array}{l}\text { Max } \\
\text { (b) } \\
(\mathrm{km})\end{array}$ \\
\hline 2000 & 31 & 0.96 & 0.928 & 0.150 & 6.991 & 0.729 & 7.091 & 0.240 & 69.200 \\
\hline 2001 & 36 & 0.95 & 0.719 & 0.138 & 5.703 & 0.688 & 8.533 & 0.150 & 56.225 \\
\hline 2002 & 33 & 0.98 & 0.833 & 0.090 & 6.141 & 0.455 & 8.320 & 0.350 & 77.850 \\
\hline 2003 & 36 & 0.99 & 0.361 & 0.025 & 4.129 & 0.116 & 4.470 & 3.540 & 47.575 \\
\hline 2004 & 18 & 0.99 & 0.493 & 0.206 & 3.336 & 1.175 & 2.860 & 0.010 & 14.100 \\
\hline 2005 & 33 & 0.98 & 0.716 & 0.090 & 5.664 & 0.495 & 4.405 & 0.320 & 60.550 \\
\hline 2006 & 24 & 0,99 & 0.500 & 0.066 & 4.333 & 0.306 & 4.757 & 1.330 & 47.575 \\
\hline 2007 & 22 & 0.99 & 0.390 & 0.043 & 5.044 & 0.306 & 5.062 & 6.440 & 51.900 \\
\hline 2008 & 32 & 0.96 & 0.762 & 0.100 & 5.810 & 0.503 & 8.158 & 0.510 & 90.825 \\
\hline 2009 & 32 & 0.97 & 0.605 & 0.049 & 4.994 & 0.235 & 3.021 & 1.640 & 51.900 \\
\hline 2010 & 43 & 0.97 & 0.901 & 0.129 & 6.920 & 0.749 & 6.354 & 0.180 & 86.500 \\
\hline 2011 & 45 & 0.96 & 0.494 & 0.038 & 4.281 & 0.203 & 3.964 & 0.800 & 47.575 \\
\hline
\end{tabular}

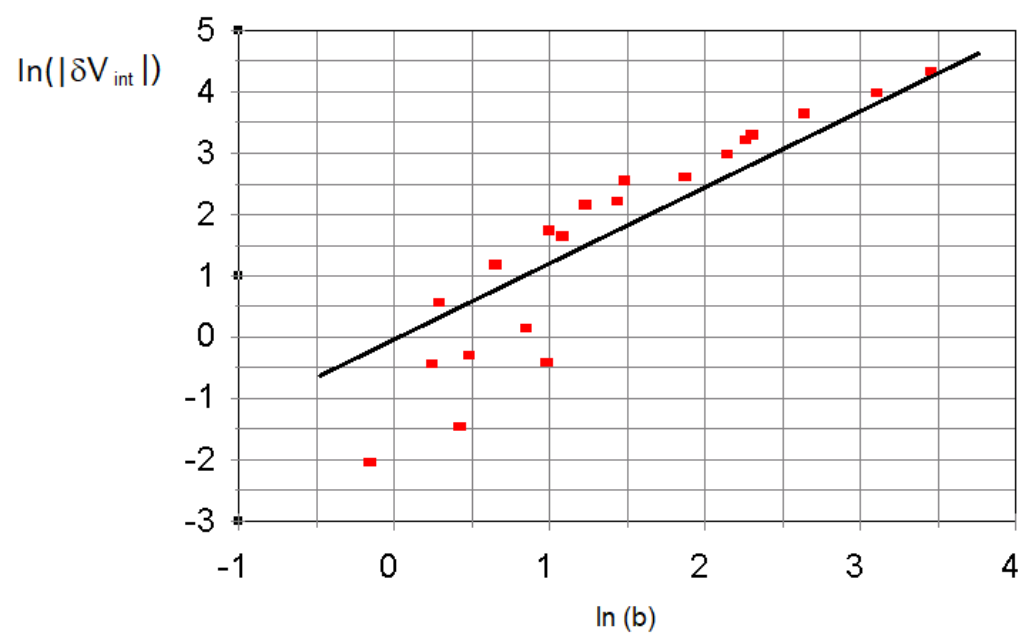

Fig. 10 Changing the parameters $\ln (b)$ and $\ln \left|\delta V_{\text {int }}\right|$ according to Table 6.

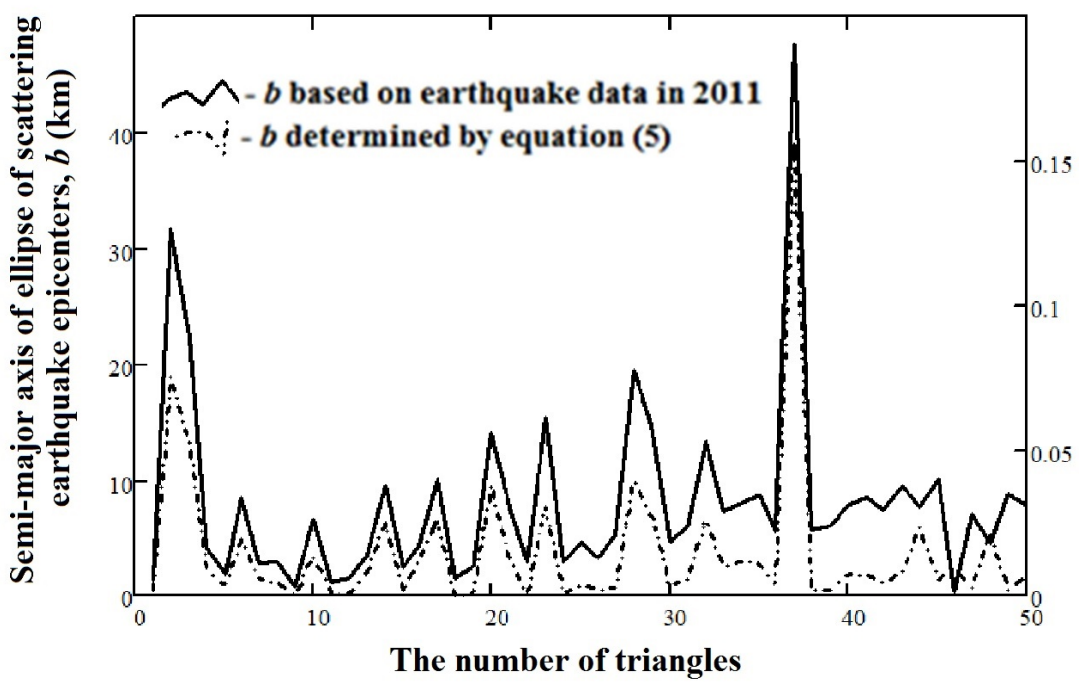

Fig. 11 Changing of semi-minor axis of ellipse of scattering earthquake epicenters and integral velocity index of the vertical displacement based on the results of 2011 data and on the results of approximating equation (5). 

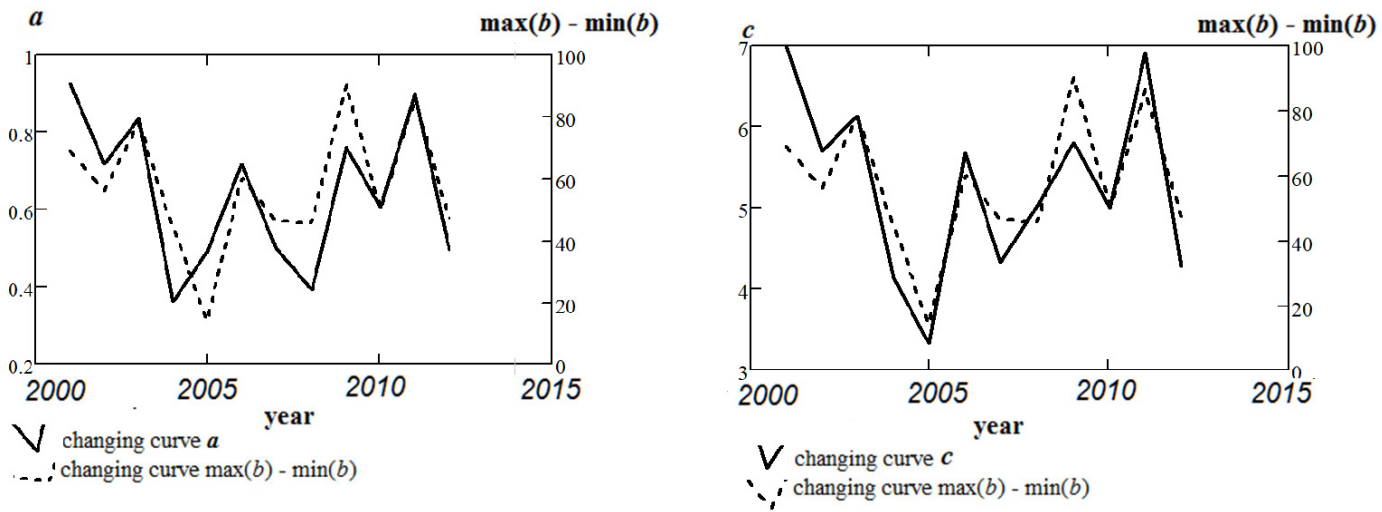

Fig. 12 Dependence of changing a) a coefficient out of $\max (b)$-min (b); b) $c$ coefficient out of $\max (b)-\min b)$.

and by the equation (7) occurred primarily during the first year of observations (from 2000 till 2001), and have a relatively small number of permanent stations and as a result their respectively formed triangles have much larger area than in the next years. Thus, the average distance between GNSS stations in 20002001 was $220 \mathrm{~km}$ and in 2010-2011 it was $150 \mathrm{~km}$. It is obvious that low level of differentiation of GNSS stations territory in 2000-2001 has some deviation of seismic and vertical displacement dependence. But there are significant abnormal deviations in 2007 data. Average square error of $\left|\delta V_{\text {int }}\right|$. by the equation (7) for all observation years is within -0.03 and $0.01 \mathrm{~km}^{3}$ per year, and it is $0.05 \mathrm{~km}^{3}$ per year based on 2007 data. It takes about $10-15 \%$ of the average values $\left|\delta V_{\text {int }}\right|$. If the maximum error of $\left|\delta V_{i n t}\right|$. value is transferd to triangle with square of $1.000 \mathrm{~km}^{2}$ it gives an error in determining the average vertical velocity, that is, exactly 0.05 .

So, the equation (7) can be considered as suitable for determining $\left|\delta V_{\text {int }}\right|$. Using maximum magnitude of small semi axes of ellipse of scattering earthquake epicenters $\max (b)$-min (b) for the European territories to the close correlative connection between $b$ and $\left|\delta V_{\text {int }}\right|$ and $b$ value of set territory, under condition that the average distance between GNSS stations is not more than $150 \mathrm{~km}$. It should be noted that the equation (7) can't be identified by a known $b$ parameter $\left|\delta V_{\text {int }}\right|$, because the $\max (b)$-min (b) must be found.

Let us consider if selected by basic measurements for different observation years territories (with close correlative connection between $b$ and $\left.\left|\delta V_{\text {int }}\right|\right)$ have spatial convergence.

\section{SPATIAL-TEMPORAL DIVISION OF EUROPEAN TERRITORIES WITH CLOSE CORRELATIVE CONNECTION BETWEEN $b$ AND $\left|\delta V_{\text {int }}\right|$}

Figure 14 shows the annual mapping of set triangles, which have close correlative connection between the vertical displacements of the Earth's surface and seismic activity based to the results of the period from 2000 till 2011. These territories coincide with these ones of stable seismic activity.
The next it is important to find territories where indifferent years display correlative connection is seen. As the configuration of triangles changes every year, different territories must be taken into consideration. In order to identify territories with sustainable in time correlative connection between $b$ and $\left|\delta V_{\text {int }}\right|$ all European territory has been divided into a grid of squares (GRID). Graphical example of the division of the territory is shown in Figure 15. The length and width of the Grid sides was $20 \mathrm{~km}$ on the place. As the result, this division has received a number of data coordinated in the apexes of quadrangles points. If the correlative connection is absent in certain triangle where this point is set it has been withdrawn out of this set. Such selection has been made for the entire observation period (from 2000 till 2011).

Thus, the territories have been set where every year close correlative connection between generalized parameters $b$ and $\left|\delta V_{\text {int }}\right|$ (Fig. 16). In this figure, the triangles are tinted within which the correlation connection between $b$ and $\left|\delta V_{\text {int }}\right|$ manifested from 5 to 11 observation years. Isolines determine the total number of years during which displayed correlative connection between studied parameters has been seen.

Many observation years have obviously (Fig. 16) shown that high correlation between the parameters $b$ and $\left|\delta V_{\text {int }}\right|$ as a rule is displayed in the mountain areas of the Alps, the Pyrenees, and some tectonic structures: the Armorican Massif in southwestern France, in the Rhine shale mountains (Rhenish Massif) and tectonic zone Teisseyre-Tornquist (Tornquist-Teisseyre fault system).

Areas with a close correlative connection between $b$ and $\left|\delta V_{\text {int }}\right|$ coincide with zones of intense seismic activity. However, there is a significant part of the areas of intense seismic activity on the European continent, for which this correlation is not characteristic.

To study the characteristics of these areas statistic analysis of the division of earthquake for observation period has been done for the set areas and for areas with high seismic activity for which no correlative connection between the integral velocity 

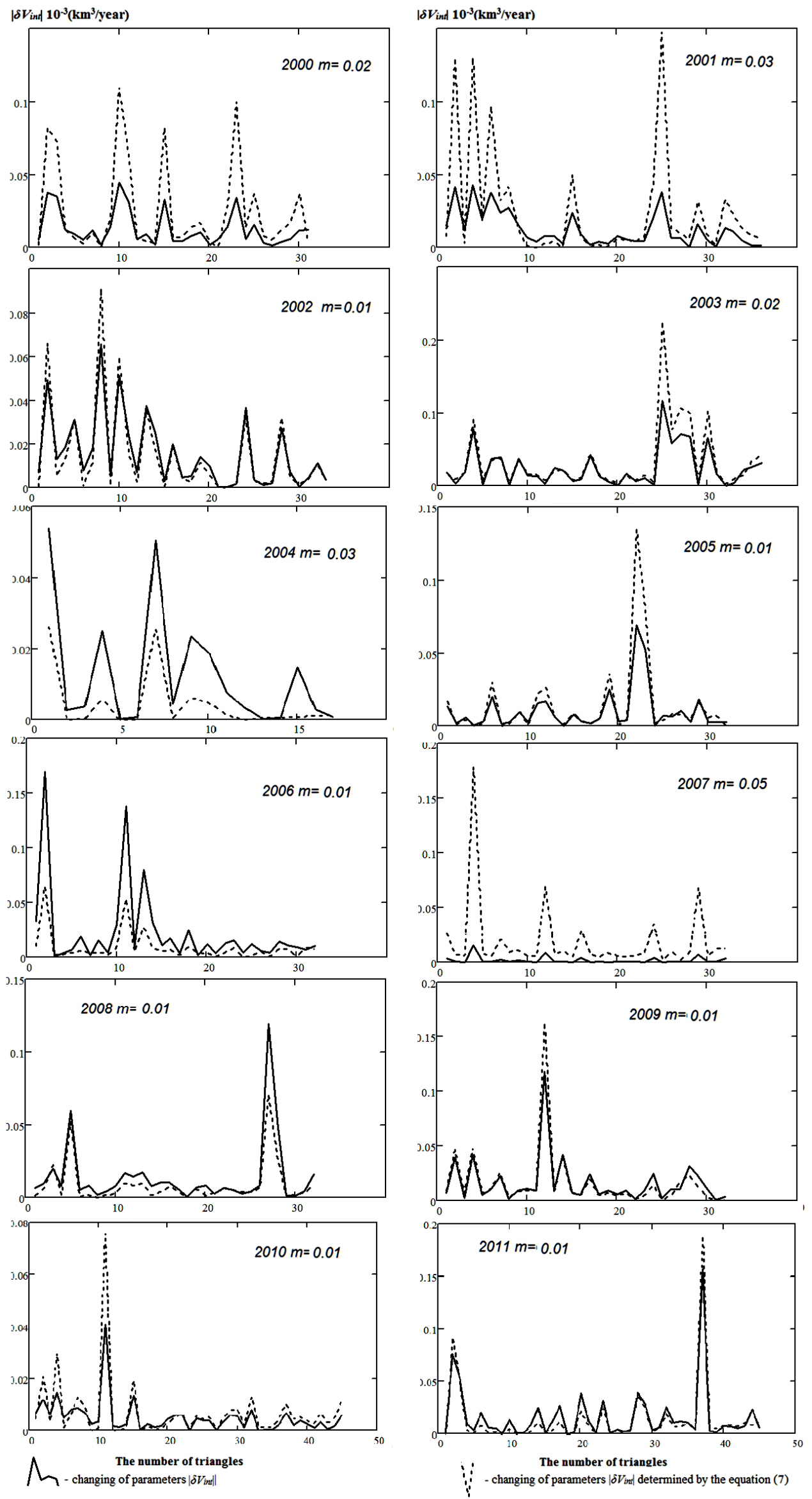

Fig. 13 Curves of changing $\left|\delta V_{\text {int }}\right|$. based on GNSS measurements and on the results of equation (7) and the average square error of abnormalities $m$ in $10^{-3}\left(\mathrm{~km}^{3}\right.$ per year). 

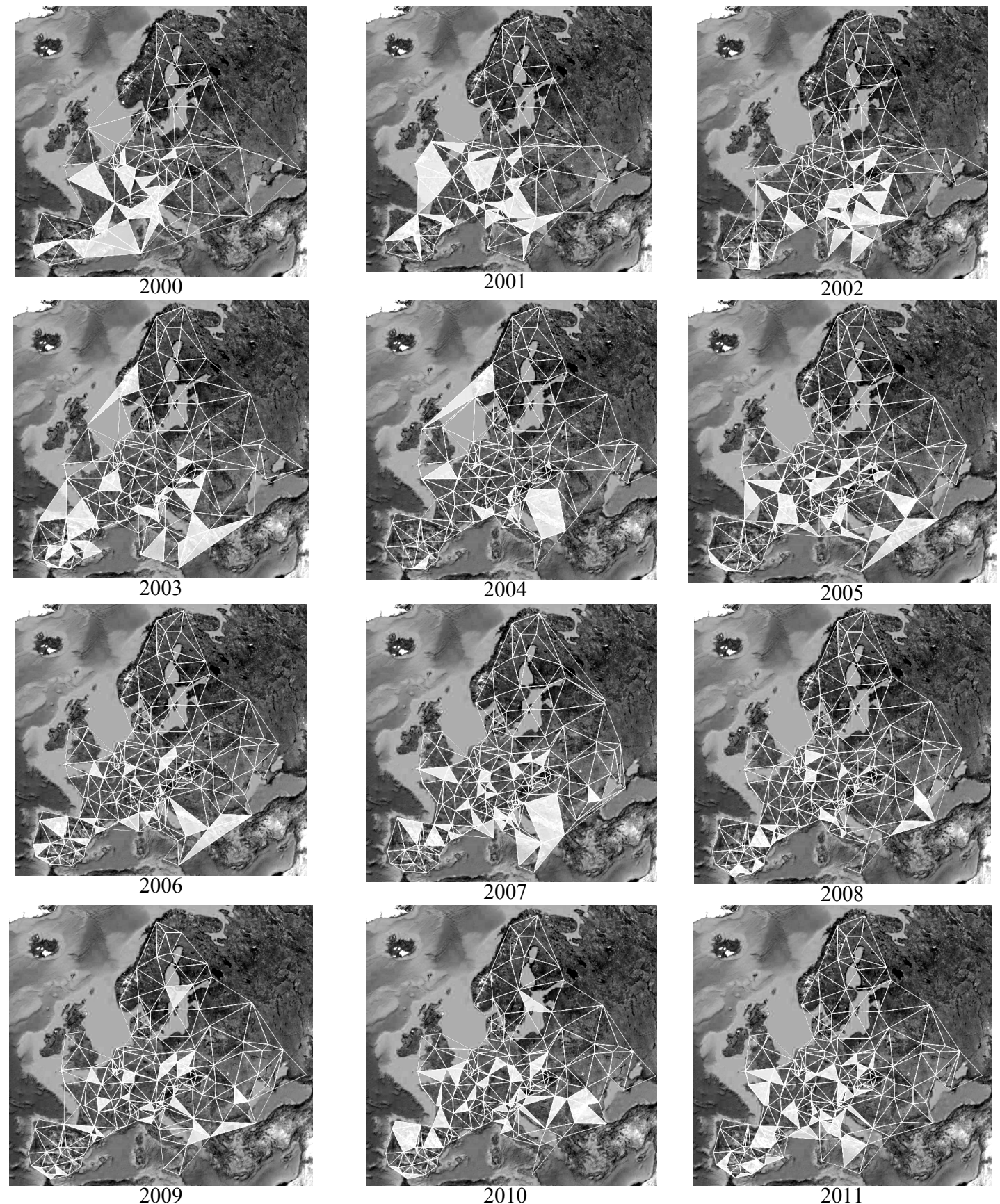

- Territories with high degree of correlative connection between the parameters

Fig. 14 Mapping of the territories covered by high degree of correlative connection between $b$ and $\left|\delta V_{\text {int }}\right|$ based on observations for the period from 2000 till 2011.

index of the vertical displacement and semi-minor axis of ellipse of scattering earthquake epicenters has been set. For example, six seismic active areas are presented in Figure 17, the first three of which (1-3) have correlation and the next three (4-6) have no correlation between these parameters.

According to the database website United States Geological Survey and the European-Mediterranean Seismological Center histogram of earthquake distribution for all six selected areas for the period from 2000 till 2011 (Fig. 18) has been constructed.
Earthquakes magnitude is in the range of 1-6 at intervals of one point.

- Location of earthquakes epicenters

- Territories with high seismic activity, where correlative connection is displayed

- Territories with high seismic activity but without correlative connection

Analyzing submitted histogram it can be established that for the first three selected areas (with the correlative connection between $b$ and $\left.\left|\delta V_{\text {int }}\right|\right)$ from 


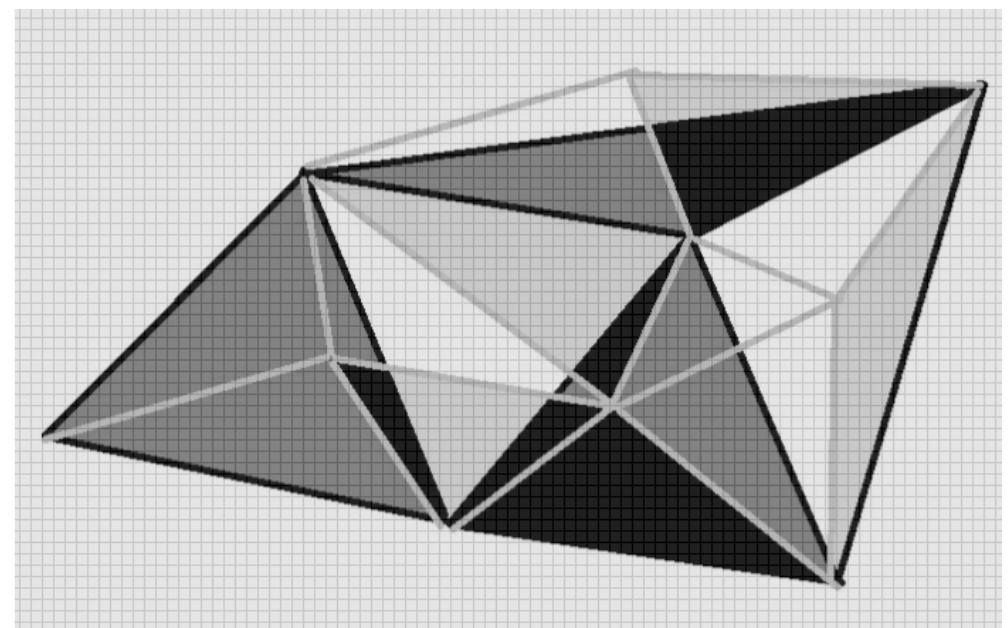

$\triangle$ - Triangle without correlative connection in 2006;

$\Delta$ - Triangle where correlative connection appeared in 2006;

- Triangle without correlative connection in 2007;

- Triangle where correlative connection appeared in 2007;

- Territories where connective correlation has appeared 2006 till 2007;

- Grid.

Fig. 15 An example of determining the territories where correlative connection between $b$ and $\left|\delta V_{\text {int }}\right|$ always exists.

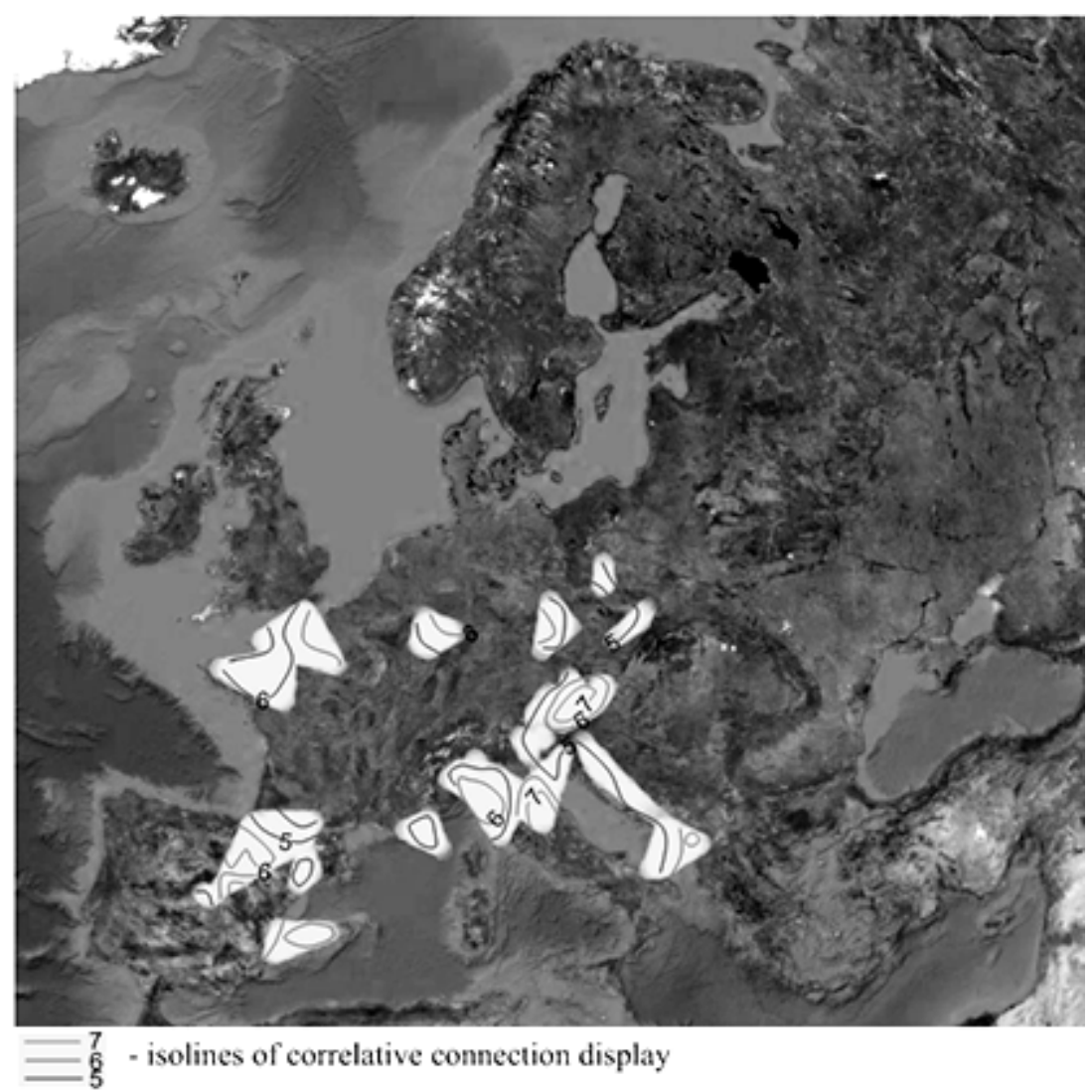

Fig. 16 Mapping territories covered by high degree of correlative connection between $b$ and $\left|\delta V_{\text {int }}\right|$ for the entire period from 2000 till 2011. 


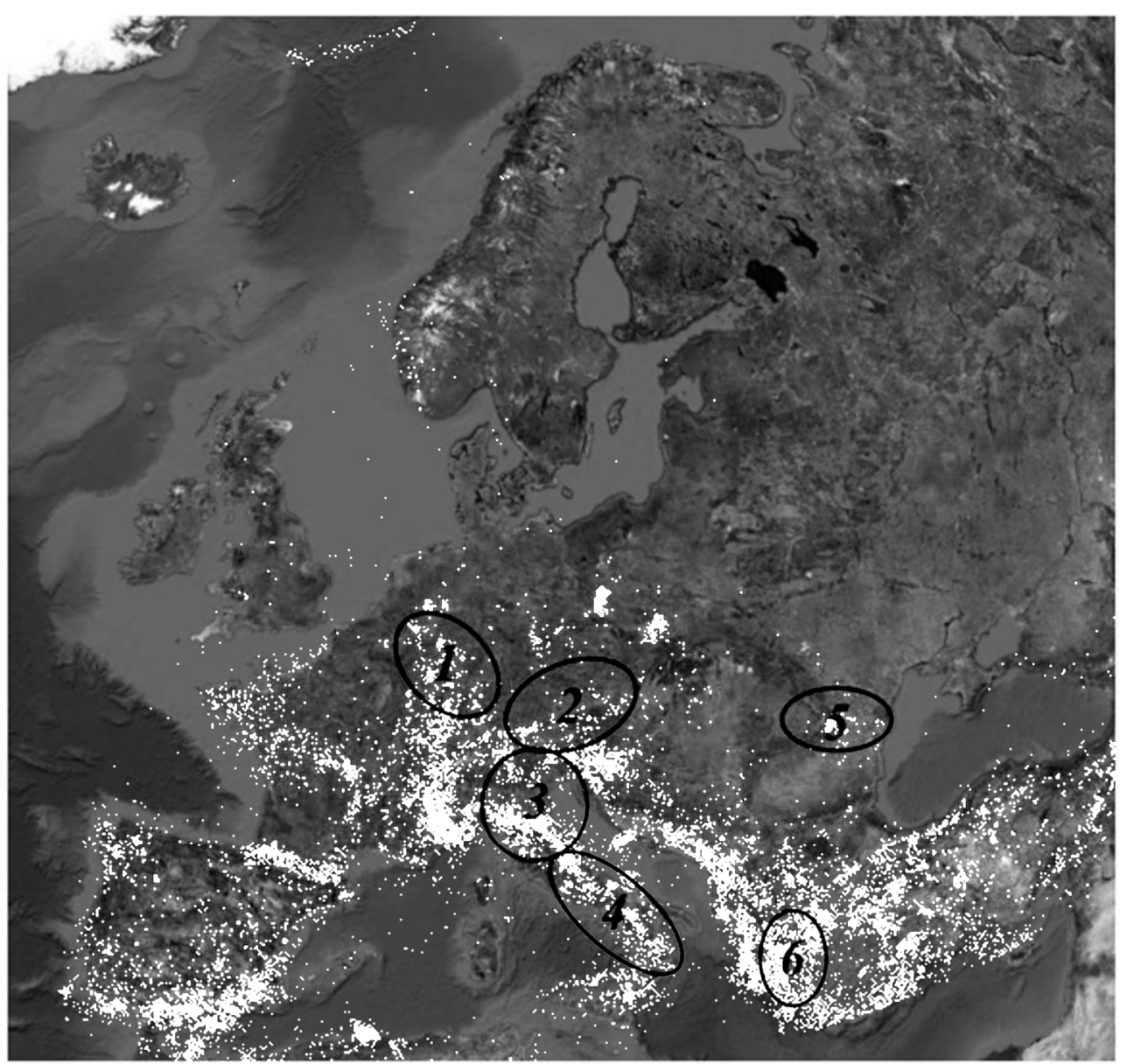

- location of esquake epicenters

\section{(D)(2) - territories with high seismic activity where correlative connection is displaying \\ (D) 50 - territories with high seismic activity withour correlative connection}

Fig. 17 Seismicity map of European researching territories.

55 to $70 \%$ earthquakes magnitude 2 is presented. There is earthquakes magnitude 1 from 10 to $30 \%$. Also, there is earthquakes magnitude 3 , which is in the range from 10 to $30 \%$. A small number of earthquakes with magnitude 4 and 5 have been registered there. But their amount does not exceed $3 \%$.

For (4-6) zones, which are without correlative connection between $b$ and $\left|\delta V_{\text {int }}\right|$ the vast majority of earthquakes magnitude 3 is from 37 to $70 \%$ and earthquakes magnitude 2 is from 16 to $49 \%$. However, earthquakes magnitude in the range from 4 to 6 is $9 \%$ and magnitude in the range from 5 to 0.7 is $2.5 \%$. And there is earthquakes magnitude 6 . Their percentage is from 0.3 to $1.2 \%$.

In general, in the area without correlative connection in comparison with the territories where present correlation is presented (Table 8 ) earthquakes magnitude is two or three times less than earthquakes of magnitude in the range from 1 to 2 and three times more than earthquakes of magnitude in the range from 3 to 4 . There are 15 times more earthquakes of magnitude 5 and magnitude 6 .
Obviously, increasing number of powerful earthquakes and the emergence of earthquakes magnitude 6 lead to losing correlation between seismicity background and vertical crust displacements. It could also be justified that complete lack of correlation on all the European territory between $\left|\delta V_{\text {int }}\right|$ and $a$ (that is semi-major axis of ellipse of scattering earthquake epicenters) is formed by powerful earthquakes.

\section{CONCLUSIONS}

To find interrelation between the vertical field velocity of the Earth's surface and seismic activity generalized criteria "integral velocity index of the vertical displacement" based on previously conducted generalized seismic criteria have been developed. Spatial and temporal division of European territory has been investigated and generalized criteria of vertical field velocity of the crust, seismic activity for the period from 2000 till 2011 have been learned.

On the basis of the developed method, according to the data from 2000 to 2011 , there were set areas for 


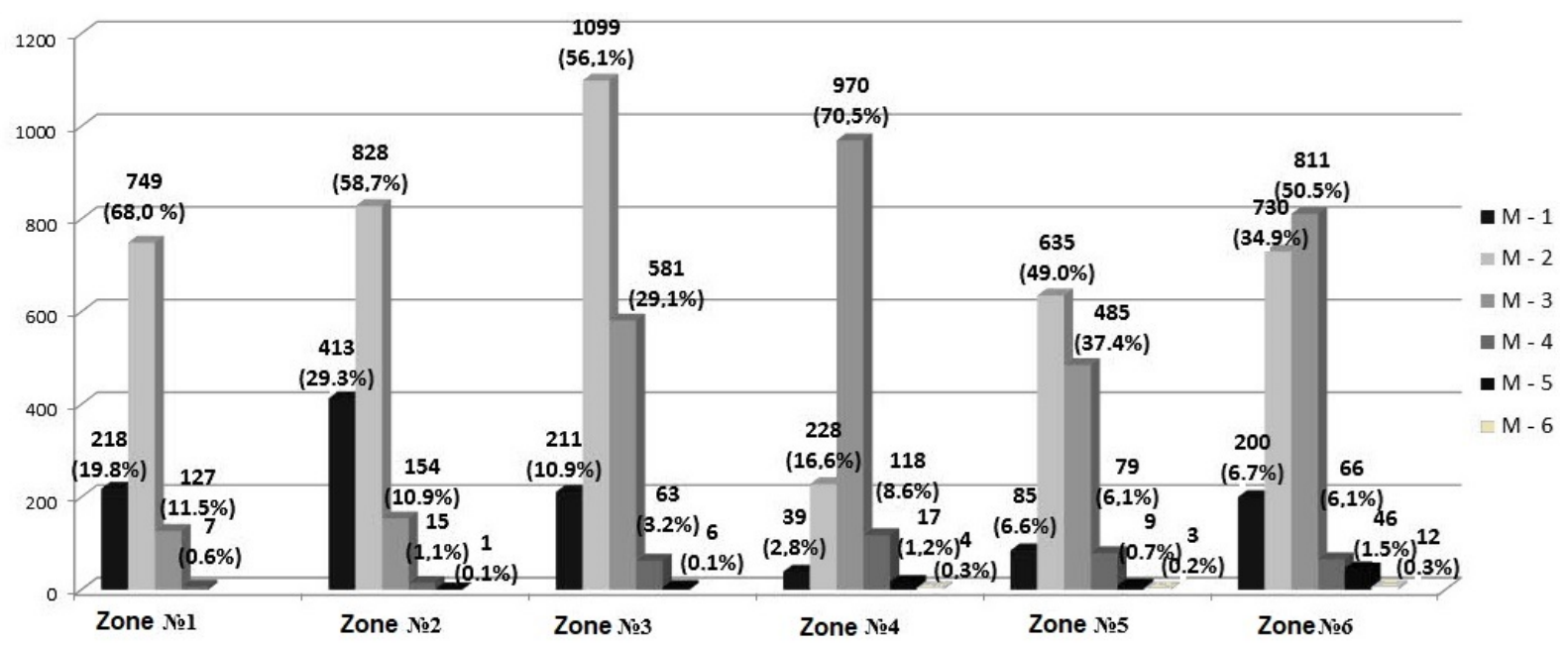

Fig. 18 Histogram of earthquakes distribution by magnitude at the set territories.

Table 8 The average statistic distribution of earthquakes of varied magnitude (in percentage) on the selected territories.

\begin{tabular}{|c|c|c|c|c|c|c|}
\hline \multirow[t]{2}{*}{ Selected territories } & \multicolumn{6}{|c|}{ Magnitude } \\
\hline & 1 & 2 & 3 & 4 & 5 & 6 \\
\hline $\begin{array}{l}1-3 \\
\text { (With the correlative connection ) }\end{array}$ & $19.9 \%$ & $60.9 \%$ & $17.4 \%$ & $1.6 \%$ & $0.1 \%$ & $0 \%$ \\
\hline $\begin{array}{l}\text { 4-6 } \\
\text { (Without correlative connection) }\end{array}$ & $6.7 \%$ & $34.9 \%$ & $50.5 \%$ & $6.1 \%$ & $1.5 \%$ & $0.3 \%$ \\
\hline
\end{tabular}

the European continent (Fig. 16) for which during 57 years the correlation coefficient between $b$ (semiminor axis of ellipse of scattering earthquake epicenters) that corresponds to the background seismicity of the territory, and $\left|\delta V_{\text {int }}\right|$ (integral index of the velocity of the vertical displacement of the territory) was within $0.95-0.99$.

For the territory with close correlative connection between $b$ and $\left|\delta V_{\text {int }}\right|$ mathematical equation has been set that enables options based on the distribution of earthquakes, such as semi-minor axis ellipse of scattering earthquake epicenters $b$ which helps to determine the integral velocity index of the vertical displacement $\left|\delta V_{\text {int }}\right|$ of a set territory. It is proved that mathematical formula can be used to determine $\left|\delta V_{\text {int }}\right|$ for the European territories with close correlative connection between $b$ and $\left|\delta V_{\text {int }}\right|$ under the condition of using GNSS stations network with the average distance between them not more than $150 \mathrm{~km}$. The established mathematical equation cannot determine that known $b$ parameter applying known $\left|\delta V_{\text {int }}\right|$, because the maximum extent of semi-minor axis of ellipse of scattering earthquake epicenters for the whole territory must be taken into account.

Taken into consideration that semi-minor axis $b$ of ellipse of scattering earthquake epicenters depends on the amount and spatial division of small magnitude earthquakes, the detected seismic active areas with close correlative connection between $b$ and $\left|\delta V_{\text {int }}\right|$ confirm the interrelation between the slow movements of the Earth's surface and background seismicity, which is caused by slack earthquakes.

Powerful earthquakes cause abnormal movements of the Erath's surface that do not have a systematic display and, therefore, it is difficult to set connection between seismicity and their movements. This is confirmed by the absence of correlation between $b$ and $\left|\delta \mathrm{V}_{\text {int }}\right|$ in seismic active European areas with earthquakes magnitude in the range from 5 to 6 and complete absence of correlative connection on the whole European territory between $\left|\delta V_{\text {int }}\right|$ and $a$ (where $a$ is a semi-major axis of ellipse of scattering earthquake epicenters) which are formed by powerful earthquakes.

The results of the research can be taken into account to predict places of altitude displacement at the European continent foundations and to conduct models of vertical movements of the Earth's surface.

These studies are not intended to predict a particular earthquake. On the basis of the developed research methodology and generalized criteria of seismicity and vertical movements of the Earth's surface, zones with a close correlation between these parameters have been established in the territory of Europe. The existence of this correlation is substantiated and functional dependencies are defined for these territories between the introduced general criteria. The continuation of these studies may allow the establishment of similar functional connections for the prediction of generalized seismic background.

\section{REFERENCES}

Abraha, K.E., Teferle, F.N., Hunegnaw, A. and Dach, R.: 2017, GNSS related periodic signals in coordinate time series from Precise Point Positioning. Geophys. J. Int., 208, 3, 1277-1289. DOI: 10.1093/gji/ggw467

Allen, R. M. and Ziv, A.: 2011, Application of real-time GPS to earthquake early warning. Geophys. Res. Lett., 38, 16, L16310. DOI: 10.1029/2011GL047947 
Altamimi, Z.: 2015, Update on the International Terrestrial Reference Frame (ITRF) and Handling Deformation Caused by Large Earthquakes. ICG-10, Boulder, USA, 1-6, November, 2015.

Ambraseys, N.N. and Sarma, S.K.: 1999, The assessment of total seismic moment. J. Earth. Eng., 3, 4, 439-461. DOI: $10.1080 / 13632469909350354$

Avallone, A., D'Anastasio, E., Serpelloni, E., Latorre, D. et al.: 2012, High-rate (1 Hz to $20 \mathrm{~Hz}$ ) GPS coseismic dynamic displacements carried out during the Emilia 2012 seismic sequence. Ann. Geophys., 55, 4, 773779. DOI: $10.4401 /$ ag-6162

Avallone, A., Latorre, D., Serpelloni, E., Cavaliere, A. et al.: 2016, Coseismic displacement waveforms for the 2016 August $24 \mathrm{Mw} 6.0$ Amatrice earthquake (central Italy) carried out from High-Rate GPS data. Ann. Geophys., 59, 5, 1-11. DOI: 10.4401/ag-7275

Blewitt, G., Hammond, W.C., Kreemer, C., Plag, H.P. et al.: 2009, GPS for real-time earthquake source determination and tsunami warning systems. J. Geod., 83, 3-4, 335-343. DOI 10.1007/s00190-008-0262-5

Bufe, C. and Perkins, D., 2005, Evidence for a global seismic-moment release sequence. Bull. Seism. Soc. Am., 95, 3, 833-843. DOI: 10.1785/0120040110

Cenni, N., Baldi, P., Loddo, F., Casula, G. et al.: 2013, Present-Day vertical kinematic pattern in the central and northern Italy from permanent GPS stations. Conference: Atti del $32^{\circ}$ Convegno Nazionale del Gruppo Nazionale di Geofisica della Terra Solida, 1821 Novembre 2013, Trieste, vol. 2.

Cenni, N., Mantovani, E., Baldi, P., Viti, M. et al.: 2012, Present kinematics of Central and Northern Italy from continuous GPS measurements. J. Geodyn., 58, 6272. DOI: $10.1016 / j . j o g .2012 .02 .004$

Cenni, N., Viti, M. and Mantovani, E.: 2015, Space geodetic data (GPS) and earthquake forecasting: examples from the Italian geodetic network. B. Geofis. Teor. Appl., Geophys. 56, 2, 129-150. DOI: 10.4430/bgta0139

Centre Sismologique Euro-Méditerranéen: Search for earthquakes - Access:

http://www.emsc-csem.org/Earthquake/index.php?filter=yes

Cheloni, D., De Novellis, V., Albano, M., Antonioli, A. et al.: 2017, Geodetic model of the 2016 Central Italy earthquake sequence inferred from InSAR and GPS data. Geophys. Res. Lett., 44, 13, 6778-6787. DOI: 10.1002/2017GL073580

Cheloni, D., Serpelloni, E., Devoti R. et al.: 2016, GPS observations of coseismic deformation following the 2016, August 24, Mw 6 Amatrice earthquake (central Italy): data, analysis and preliminary fault model. Ann. Geophys., 59, Fast Track 5.

DOI: 10.4401/ag-7269

Dambara, T.: 1966, Vertical movements of the Earth's crust in relation to the Matsushiro earthquake. J. Geod. Soc. Jpn., 12, 1, 18-45, (in Japanese with English abstract).

Desai, S., Bertiger, W., Gross J. et al.: 2016, Introduction to JPL's GPS time series. California Institute of Technology, under a contract with the National Aeronautics and Space Administration.

Devoti, R., D'Agostino, N., Serpelloni, E., Pietrantonio, G. et al.: 2017, A combined velocity field of the Mediterranean region. Ann. Geophys., 60, 2, 2-17. DOI: 10.4401/ag-7059

Dong, D., Fang, P., Bock, Y., Cheng, M. and Miyazaki, S.: 2002, Anatomy of apparent seasonal variations from GPS-derived site position time series. J. Geophys. Res., Solid Earth, 107, B4, ETG 9-1-ETG 9-16. DOI: $10.1029 / 2001 \mathrm{jb} 000573$
EPOS - European surveillance system for plates [electronic resource] - Access to the pro/ty: http://www.epos-eu.org/

Esposito, A., Pietrantonio, G., Bruno, V., Anzidei, M. et al.: 2015, Eighteen years of GPS surveys in the Aeolian Islands (southern Italy): Open data archive and velocity field. Ann. Geophys., 58, 4, 2-12. DOI: $10.4401 /$ ag-6823

EUREF Permanent GPS Network: Station Coordinates and Velocities - Access mode:

http://www.epncb.oma.be/ organisation/about.php

Fang, P.: 2002, Analysis of seasonal signals in GPS position time series. Scripps Institution of Oceanography, University of California, San Diego, USA.

Fernandes, R.: 2014, Current Status of EPOS GNSS Working Group. International Conference EUREF 2014, Lithuania, Vilnius. Access:

http://www.euref.eu/symposia/2014Vilnius/02-02-Fernandes.pdf

Gregersen, S. and Basham, P.W. (eds.): 2012, Earthquakes at North-Atlantic Passive Margins: Neotectonics and Postglacial Rebound. Nato Science Series C. Springer Science \& Business Media, 716 pp.

Gruszczynska, M., Klos, A., Rosat, S. and Bogusz, J.: 2017, Deriving common seasonal signals in GPS position time series by using Multichannel Singular Spectrum Analysis. Acta Geodyn. Geomater., 14, 3 (187), 273284. DOI: 10.13168/AGG.2017.0010

Hatanaka, Y., Iizuka, T., Sawada, M. et al.: 2003, Improvement of the analysis strategy of GEONET. Bulletin of the Geographical Survey Institute, 49, 1137.

He, X., Hua, X., Yu, K. et al.: 2015, Accuracy enhancement of GPS time series using principal component analysis and block spatial filtering. Adv. Space Res., 55, 5, 1316-1327. DOI: 10.1016/j.asr.2014.12.016

Ihde, J. and Augath, W.: 2001, The Vertical Reference System for Europe. EUREF Symposium in Tromsö, June 22-24, 2000. Veröffentlichung der Bayerischen Kommission für die Internationale Erdmessung, München, 61, 99-110.

Ihde, J. and Augath, W.: 2002, The European Vertical Reference system (EVRS), its relation to a World Height System and to ITRS. Proc. IAG 2001 Scientific Assembly, Budapest, Hungary. IAG Symposia, Vol. 125, 78-83.

International Service (IGS) GNSS-Access: http://www.igs.org/

Jeffreys, H.: 2008, The Earth: Its Origin, History and Physical Constitution. Cambridge University Press; 6th edition $612 \mathrm{pp}$.

Joó, I.: 1998, Vertical movements in Hungary. Geod. Kartog., 50, 9, 3-8.

Jung, H.-S. and Hong, S.-M.: 2017, Mapping threedimensional surface deformation caused by the 2010 Haiti earthquake using advanced satellite radar interferometry. PLoS ONE, 12, 11. DOI: 10.1371 /journal.pone. 0188286

Klos, A. and Bogusz, J.: 2017, An evaluation of velocity estimates with a correlated noise: case study of IGS ITRF2014 European stations. Acta Geodyn. Geomater., 14, 3 (187), 261-271. DOI: 10.13168/AGG.2017.0009

Lidberg, M., Altamimi, Z., Bruyninx, C. et al., 2014: Report from EUREF w.g. on Deformation models. Presentation at the EUREF Symposium in Vilnius, June 4-7, 2014. - Access to articles:

http://www.euref.eu/symposia /2014Vilnius/03-01-Lidberg.pdf 
Liu, J., Fang, R. and Shi, C.: 2012, Recent Progress on GNSS Seismology. In: Global Navigation Satellite Systems. Report of a Joint Workshop of the National Academy of Engineering and the Chinese Academy of Engineering, Washington.

Lu, Z., Wright, T. and Wicks, C.: 2003, Deformation of the 2002 Denali fault earthquakes, mapped by Radarsat-1 interferometry. Eos, 84, 41, 425, 430-431.

Marchenko, O. M., Tretyak, K.R., Yarema, N. P.: 2013, Reference systems in geodesy. Lviv Polytechnic National University, 215pp, (in Ukrainian).

Métivier, L., Collilieux, X., Lercier, D. et al.: 2014, Global co-seismic deformations, GNSS time series analysis and earthquake scaling laws. J. Geophys. Res., Solid Earth, 119, 12, 9095-9109.

DOI: $10.1002 / 2014 J B 011280$

Mladenovski, M., Belyashki, T. and Burilkov, T.: 1985, Map of the contemporary vertical movements of the Earth's crust for the territory of Bulgaria. A part of the Map of the contemporary vertical movements in the Carpathian-Balkan Region, scale 1:1 $000 \quad 000$. Budapest.

National Earthquake Information Center: Rectangular Area Earthquake Search - Access: http://earthquake.usgs.gov/earthquakes/eqarchives/epic/

Pancha, A., Anderson J.G. and Kreemer, C.: 2006, Comparison of seismic and geodetic scalar moment rates across the basin and range province. Bull. Seism. Soc. Am., 96, 1, 11-32. DOI: 10.1785/0120040166

Panza, G. F., Peresan, A., Sansò, F. et al.: 2017, How geodesy can contribute to the understanding and prediction of earthquakes. Rend. Fis. Acc. Lincei. DOI: $10.1007 / \mathrm{s} 12210-017-0626-\mathrm{y}$

Pospíšil, L., Švábenský, O., Roštinský, P, Nováková, E. and Weigel, J.: 2017, Geodynamic risk zone at northern part of the Boskovice Furrow. Acta Geodyn. Geomater., 14, 1(185), 113-129.

DOI: $10.13168 /$ AGG.2016.0033

Riguzzi, F., Crespi, M., Devoti, R., Doglioni, C. et al.: 2012, Geodetic strain rate and earthquake size: New clues for seismic hazard studies. Phys. Earth Planet. Inter., 206-207, 67-75. DOI: 10.1016/j.pepi.2012.07.005

Riguzzi, F., Crespi, M., Devoti, R., Doglioni, C. et al.: 2013, Strain rate relaxation of normal and thrust faults in Italy. Geophys. J. Int., 195, 2, 815-820.

DOI: $10.1093 /$ gji $/$ ggt304

Rudenko, S., Schoen N., Uhlemann, M. and Gendt, G.: 2013, Reprocessed height time series for GPS stationsSolid Earth, 4, 1, 23-41.

DOI: $10.5194 / \mathrm{se}-4-23-2013$

Santamaría-Gómez, A.: 2010, Estimation of crust vertical movements with GPS in a geocentric frame, within the framework of the TIGA project. Earth Sciences, Observatoire de Paris, 253 pp.
Selvaggi., Castello, B. and Azzara, R.: 1997, Spatial distribution of scalar seismic moment release in Italy (1983-1996): Seismotectonic implications for the Apennines. Ann. Geofys., 11, 6, 1565-1578. DOI 10.4401/ag-3832

Sobolev, S. V., Babeyko, A. Y., Wang, R. et al.: 2007, Tsunami early warning using GPS-Shield arrays. J. Geophys. Res., Solid Earth, 112, B08415. DOI: $10.1029 / 2006 J B 004640$

Stenmark, J.: 2014, Precise to a fault: How GPS revolutionized seismic research. Access http://www.earthmagazine.org/article/precise-fault-how-gpsrevolutionized-seismic-research.

The Global Geodetic Observing System (GGOS) - Access: http://www.hpplag.com/publications/cont_books.php

Tretyak, K. and Romaniuk, V.: 2013, Using GNSS technologies for research features vertical movements of the crust of Europe. Geomatics and Environmental Engineering, 7, 2, 71-77. DOI: 10.7494 /geom.2013.7.2.71

Tretyak, K.R. and Maksimchuk, V. Yu et al.: 2015, Recent geodynamics and geophysical fields of Carpathians and adjusting territories. Monography, Lviv, 320 pp., (in Ukranian).

Tretyak, K.R., Serant, O. and Smirnova, O.: 2008, The connection between the horizontal deformations of the earth's surface and the seismic activity of central Europe, Suchasni dosyagnennya geodezichnoï nauki ta virobnitstva, (in Ukrainian).

Tretyak, K.R., Smirnova, O.M. and Bredeleva, T.M.: 2012, Study of periodic changes of the world satellite permanent stations altitudes. Geodynamics, 12, 1, 1129, (in Ukranian with English abstract).

Torge, V.: 1999, Gravimetry. Moskva, Mir, 429 pp., (in Russian).

Yokoyama, I. and Nazzaro, A.: 2002, Anomalous crustal movements with low seismic efficiency - Campi Flegrei, Italy and some examples in Japan. Ann. Geophys., 45, 6, 709-722. DOI: 10.4401/ag-3543

Yurkevich, O.I.: 1964, Slow movements of the Earth's crust and the creation of earthquakes. Tectonophysics, 1, 3, 207-209. DOI: 10.1016/0040-1951(64)90001-0

Zaliapin, I. and Kreemer, C.: 2017, Systematic fluctuations in the global seismic moment release. Geophys. Res. Lett., 44, 10, 4820-4828. DOI: $10.1002 / 2017$ GL073504 